\title{
Wearable electrochemical biosensors for monitoring performance athletes
}

\section{$24 / 08 / 11$}

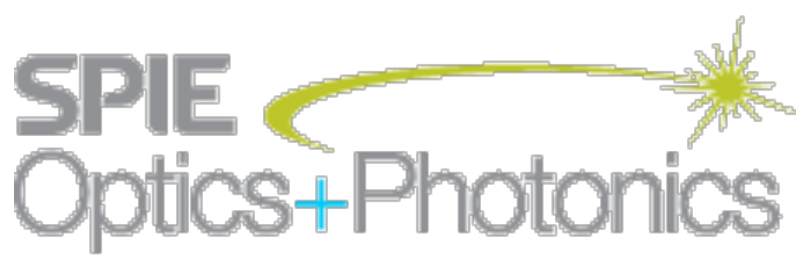




\title{
Wearable electrochemical biosensors for monitoring performance athletes
}

\author{
$24 / 08 / 11$
}

\section{@ cyrusmekon \#SPIE}




\section{Contents}

- The need for wearable sensors.

- Wearable electrochemical sensors.

- Diverse material for sensing platforms.

- Ionic Liquids

- Electrochemical biosensing: The road ahead.

- Ionogels

Conclusions. 


\section{National Centre for Sensor Research}

\section{$\mathbb{N}$ CLARITY

- Over $260 \mathrm{f} / \mathrm{t}$ researchers and support staff

- 23 affiliated faculty

- Investments and income since 1999 now approaching $€ 100$ million

- $1500 \mathrm{~m}^{2}$ well-equipped specialist lab space and offices

- Phase II expansion completed 2008 $\left(1300 \mathrm{~m}^{2}\right)$

CLARITY

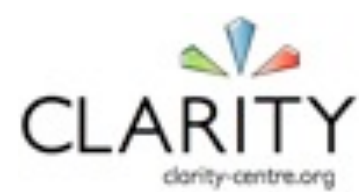

The Centre for Sensor Web Technologies
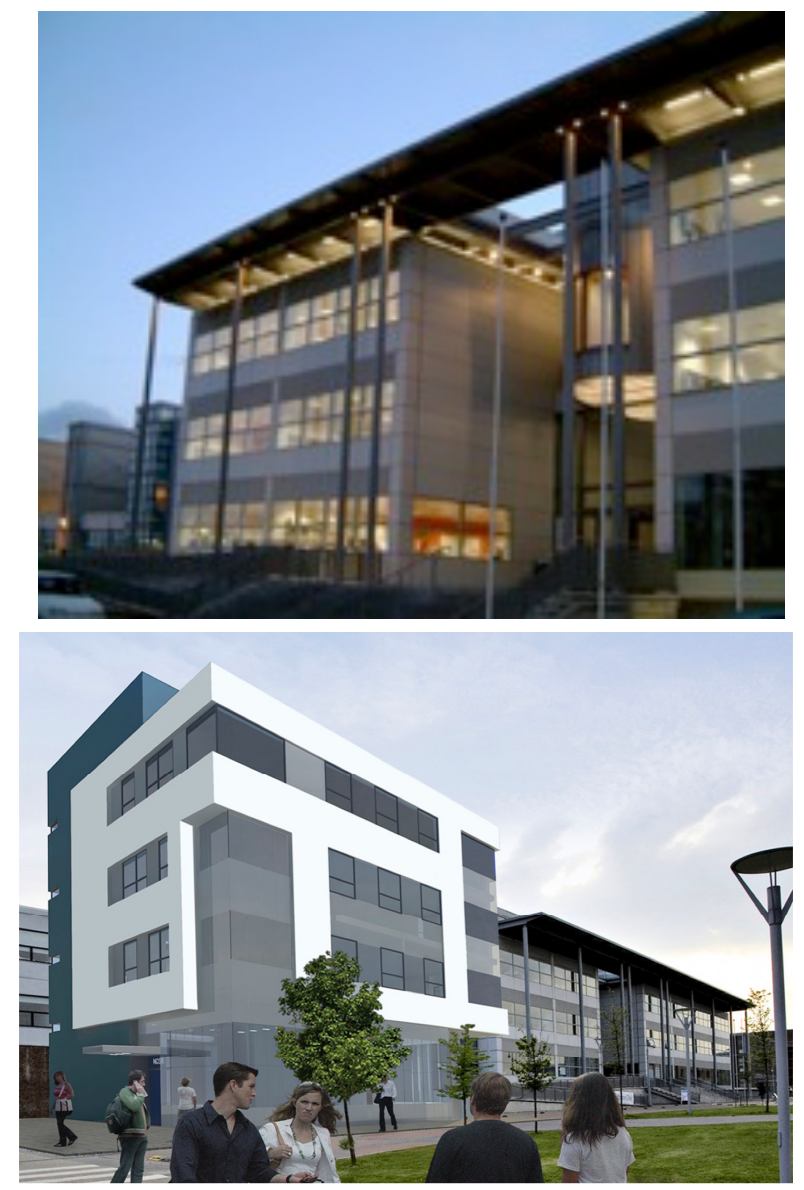

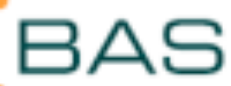

Centre for

BioAnalytical Science日

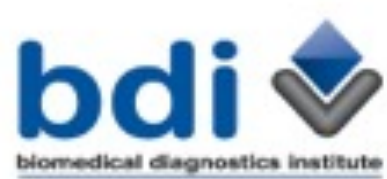

biomedical dagnostics inatitute
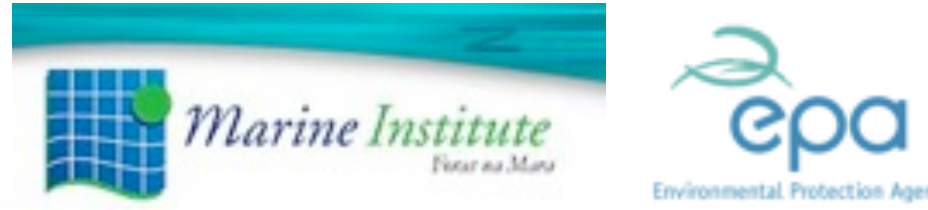

ONCSR 


\section{National Centre for Sensor Research}

\section{$\mathbb{N}$ CLARITY}

- Over $260 \mathrm{f} / \mathrm{t}$ researchers and support staff

- 23 affiliated faculty

- Investments and income since 1999 now approaching $€ 100$ million

- $1500 \mathrm{~m}^{2}$ well-equipped specialist lab space and offices

- Phase II expansion completed 2008 $\left(1300 \mathrm{~m}^{2}\right)$

CLARITY

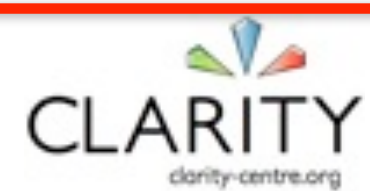

The Centre for Sensor Web Technologies
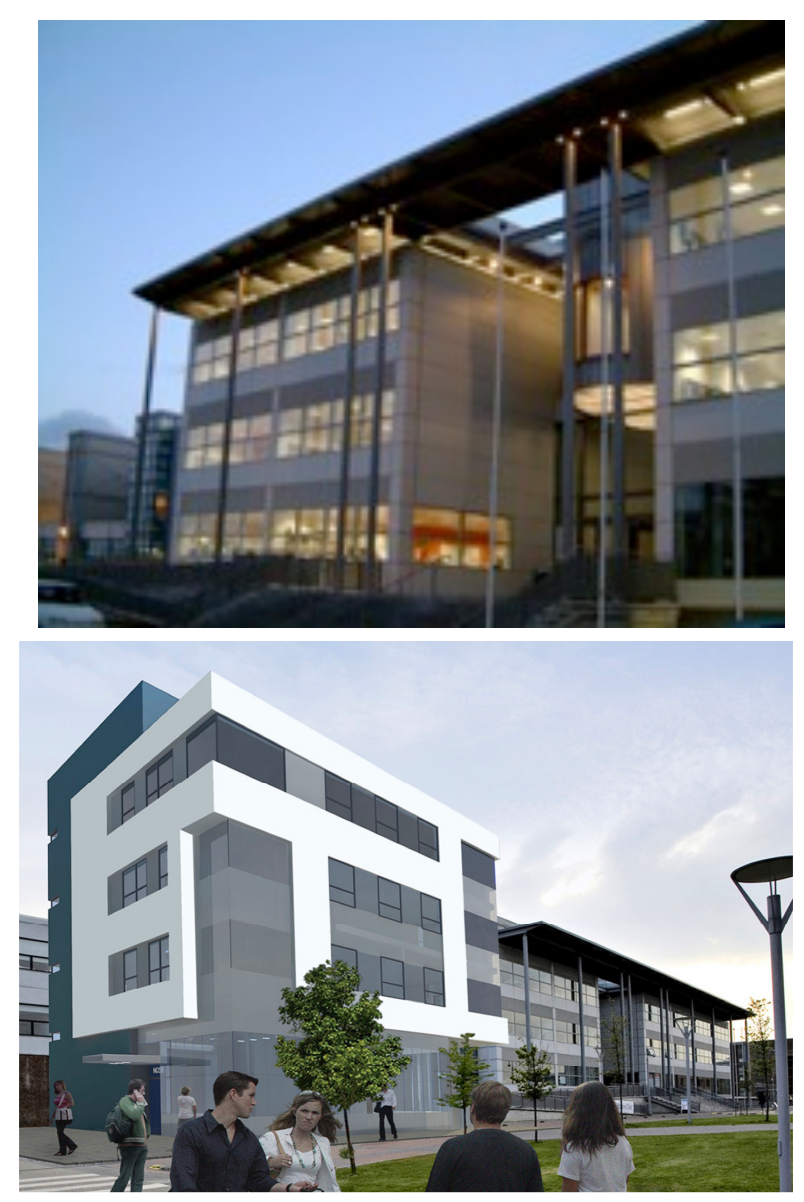

\section{BAS}

Centre for

BioAnalytical Science日

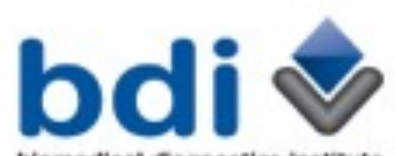

bicmedical dagnostics institute
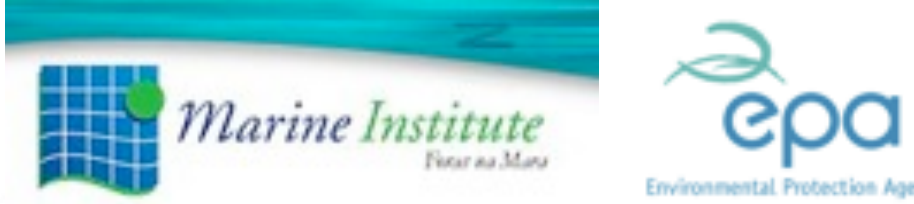

(O) NCSR 


\section{CLARITY - SFI CSET}

Vision: Sensing Mind, Body \& Place

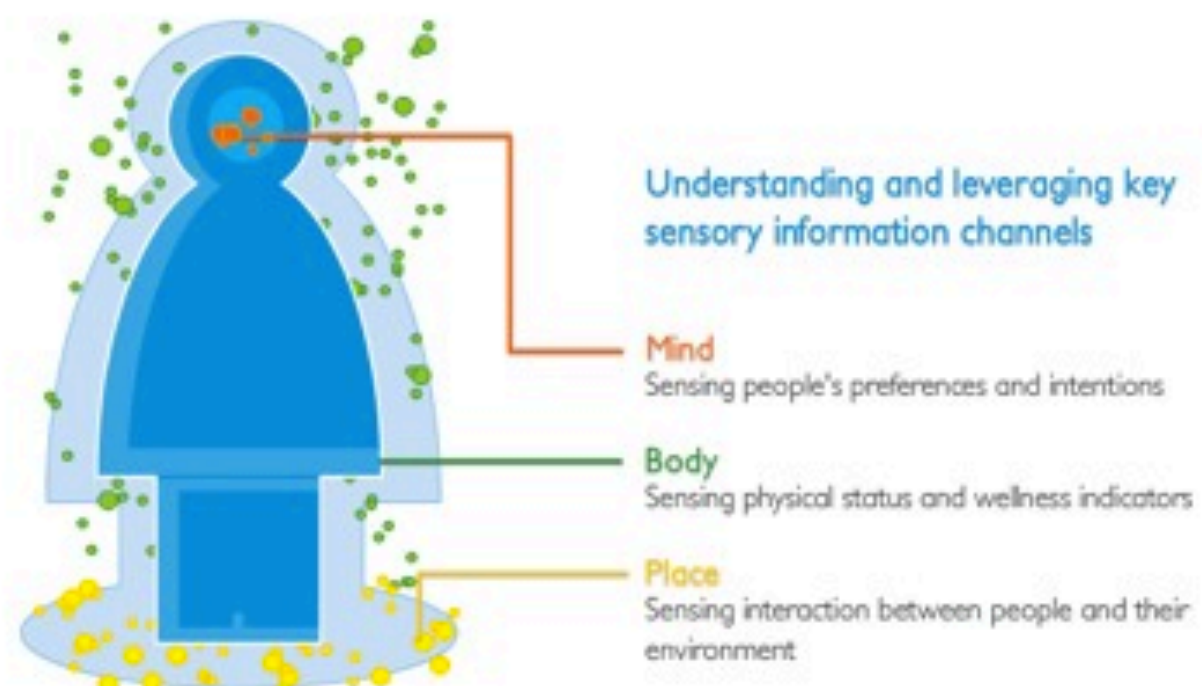

- $\quad$ 5-year, $€ 16.4$ million research program to develop next generation Sensor Web Technologies with significant environmental focus

- Brings together fundamental materials science, functional polymers, device prototyping, energy management, adaptive middleware, wearable sensors, distributed environmental monitoring. 


\section{CLARITY - SFI CSET}

Vision: Sensing Mind, Body \& Place

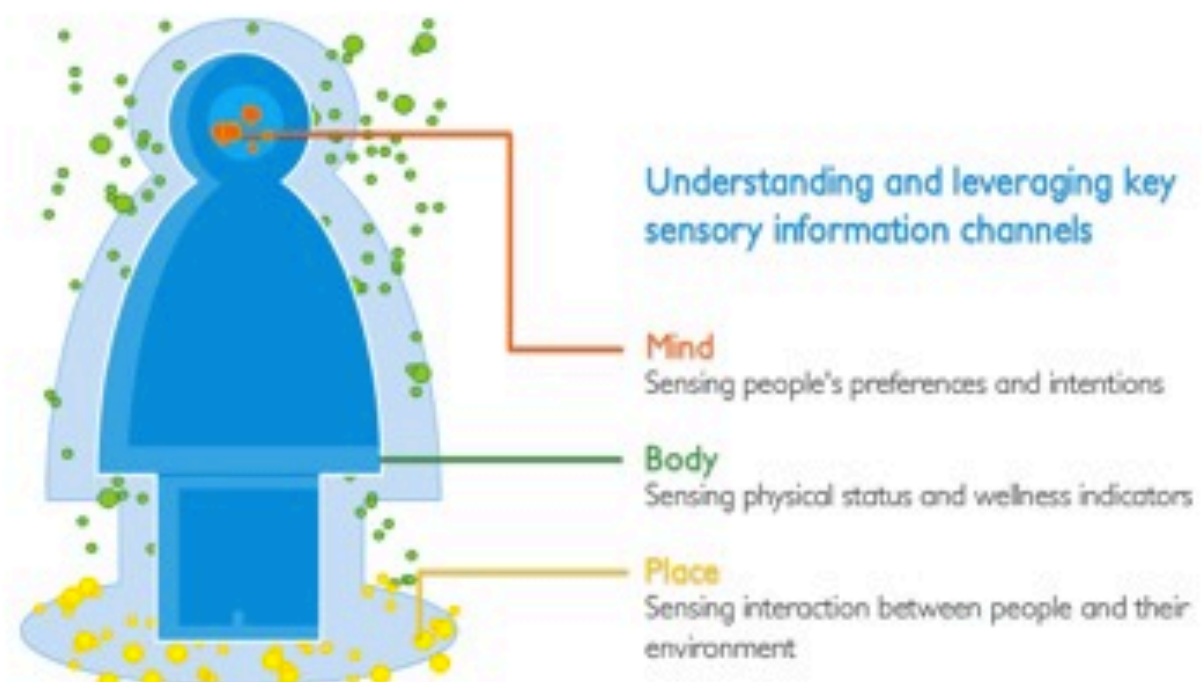

- $\quad$ 5-year, $€ 16.4$ million research program to develop next generation Sensor Web Technologies with significant environmental focus

- Brings together fundamental materials science, functional polymers, device prototyping, energy management, adaptive middleware, wearable sensors, distributed environmental monitoring. 


\section{CLARITY Centre \& Ecosystem}

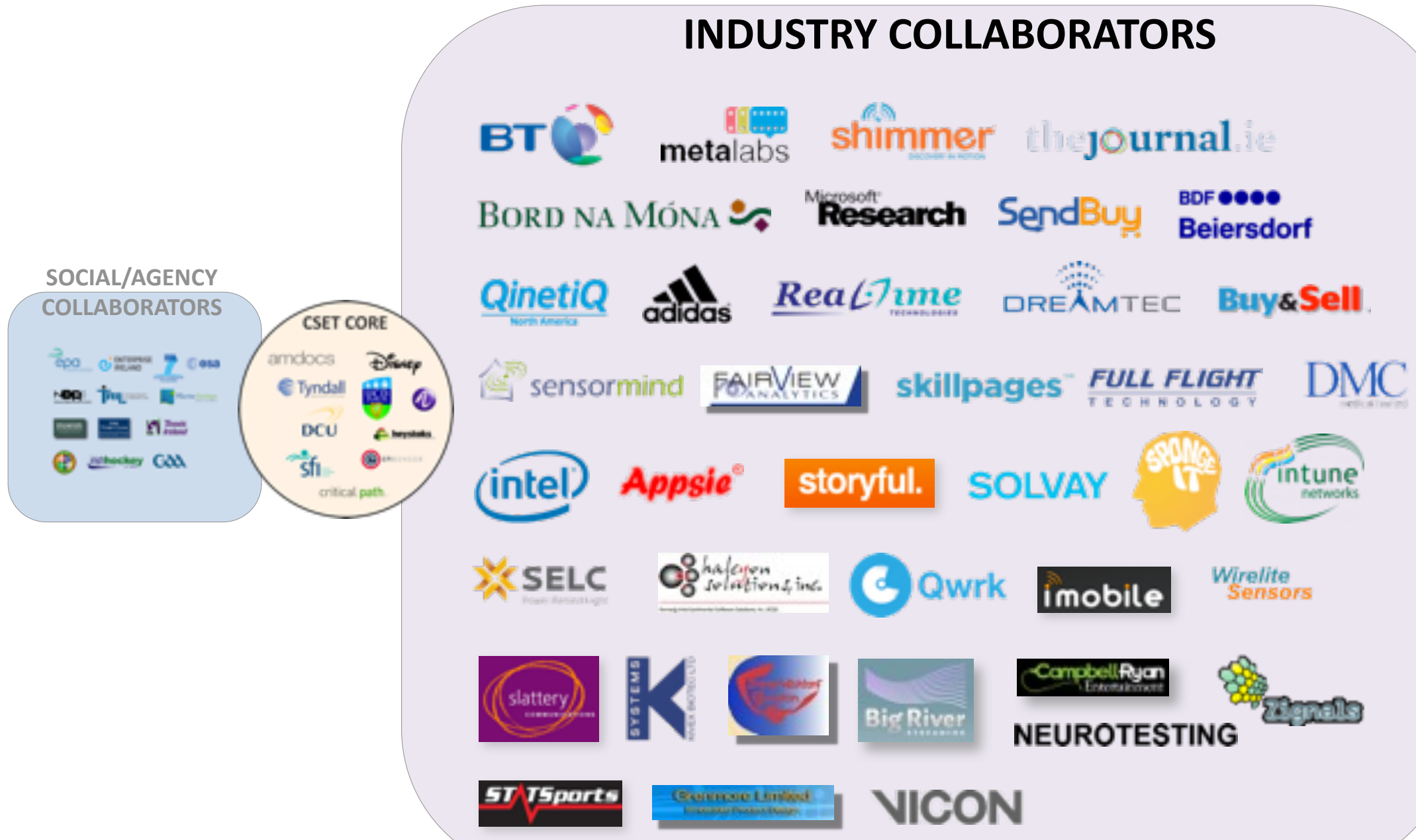

ONCSR 


\section{The need for wearable sensors.}

- Wearable sensors allow the continuous monitoring of a person's physiology in a natural setting.

- Health-monitoring systems using electronic textiles are mainly targeting applications based upon physiological parameter measurements, such as body movements or electrocardiography (ECG).

- However, due to their relative complexity, there is very little activity in the development of real-time wearable chemo/bio sensing for sports applications. 


\section{The need for wearable sensors.}

- In this field, wearable sensors are becoming increasingly employed, through the use of embedded transducers or smart fabrics for monitoring parameters like breathing rate, heart rate and footfall.

- These sensors require that the desired sample of analysis, usually a body fluid such as sweat is delivered to the sensor's active surface, whereupon a reaction happens and a signal is generated.

- Moreover the system must be low cost, while still being robust, miniature, flexible, washable, reusable or disposable[1]. 


\section{The need for wearable sensors.}

- All these requirements point to micro-fluidic devices as the key tools for improving wearable chemo-/bio-sensing[2].

- To open a dramatically wider field of applications, chemical measurements on body fluids (blood, sweat, saliva and urine) are needed.
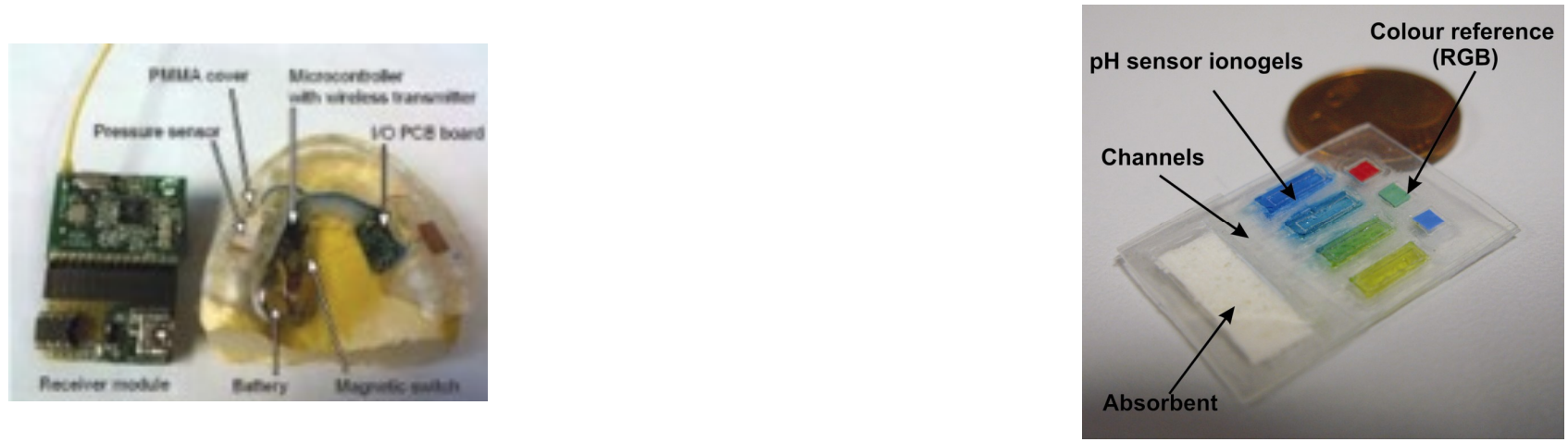


\section{The need for wearable sensors.}

- This area of research is unfortunately still poorly developed due to the difficulty in sampling such fluids. The BIOTEX project tackled some of these problems by developing a textile-based system to collect and analyze sweat by using a textile-based sensor capable of performing chemical measurements[1].

- The great advantage of analyzing sweat for health monitoring is that it is noninvasive, reasonably accessible, with the potential to provide valuable physiological information[3].

- However, advances in this direction have been limited due to the difficulty in obtaining uncontaminated samples. 


\section{In-house UV Sensor}

CLARITY
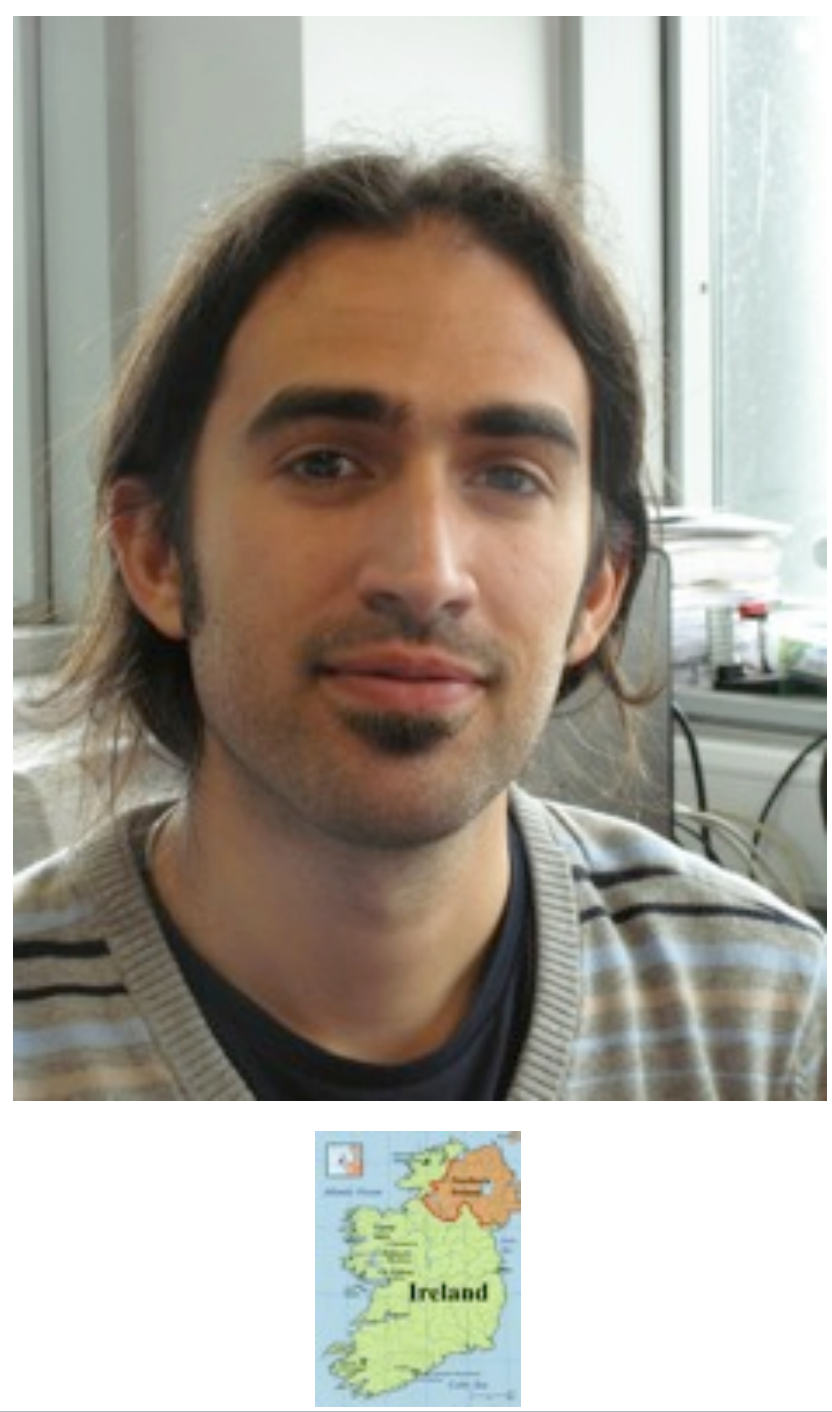

ONCSR

\section{0 of 39}

UNIVERSITY COLLEGE DUBLIN • DUBLIN CITY UNIVERSITY • TYNDALL NATIONAL INSTITUTE

Thursday, 25 August 11 


\section{In-house UV Sensor}

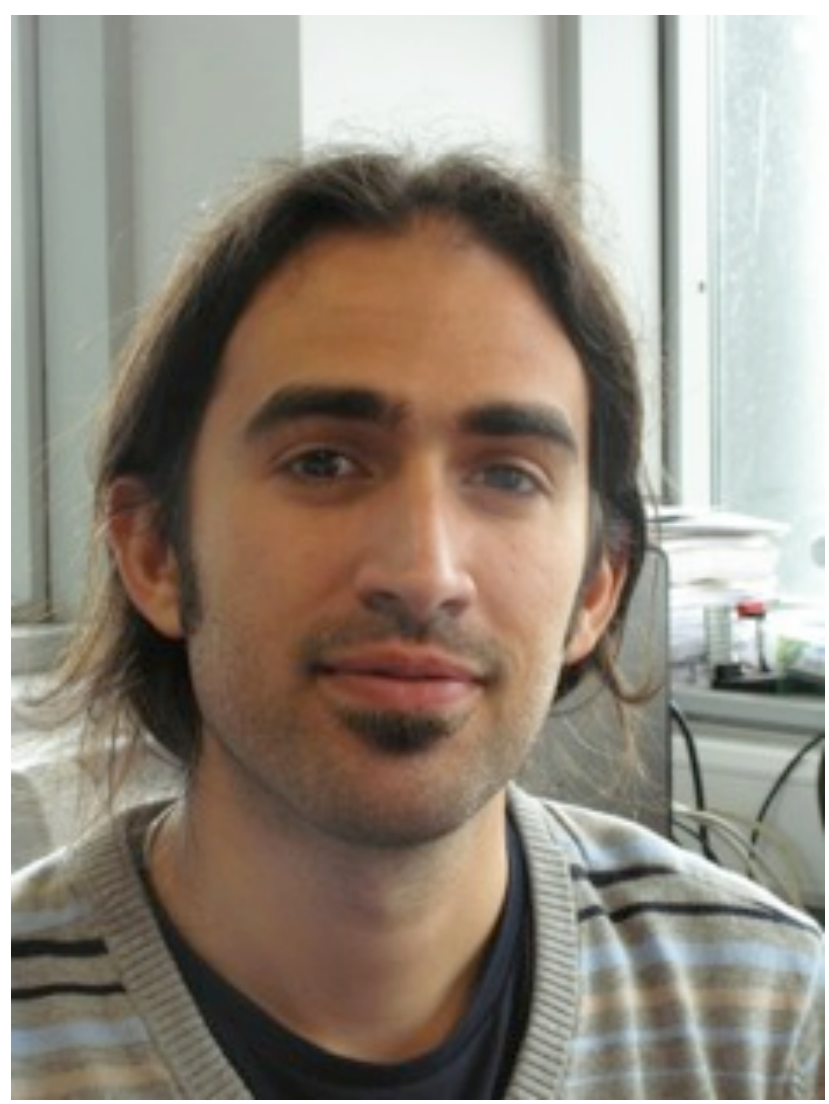

\section{2 hrs Sicily}
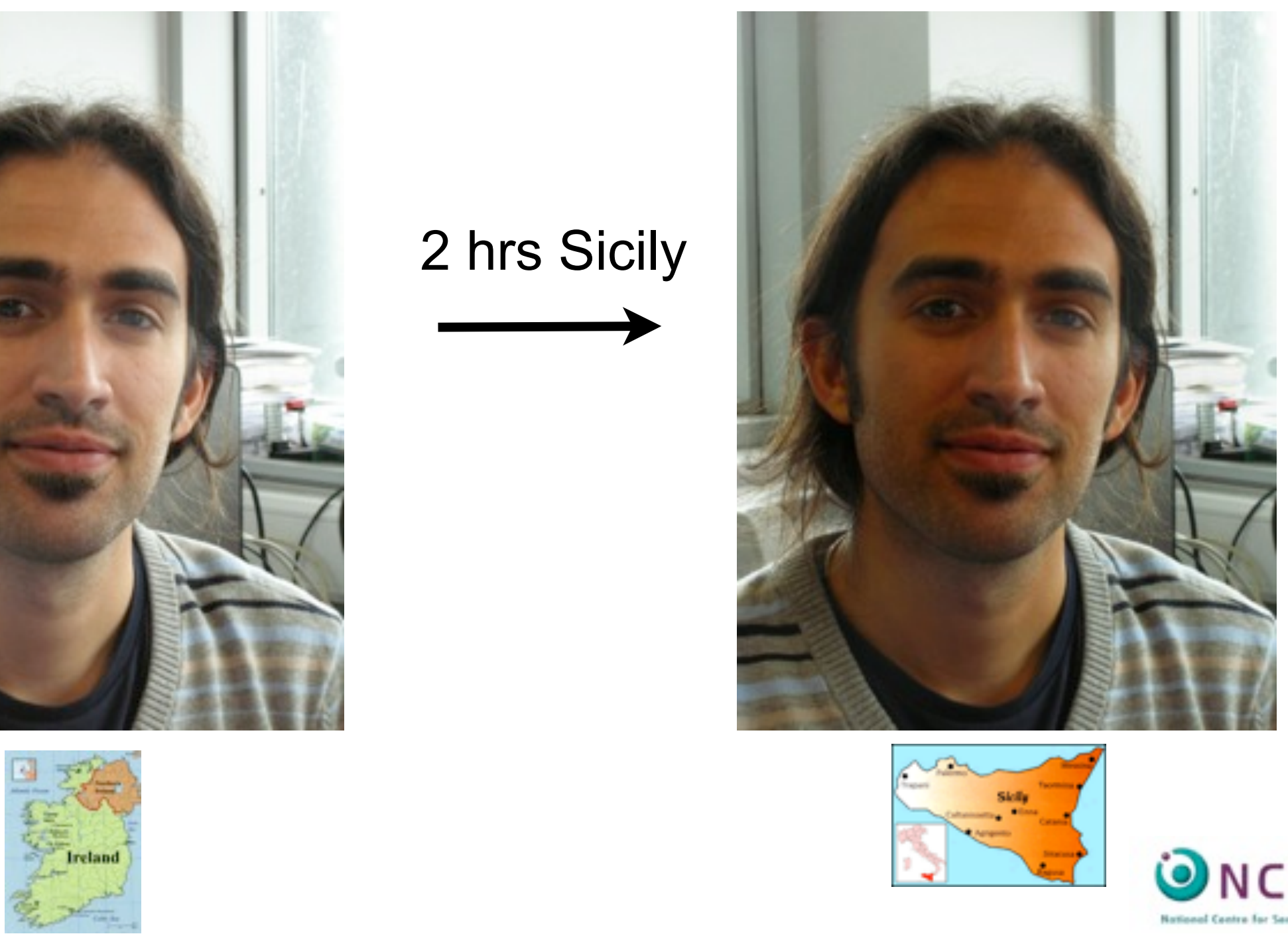

ONCSR 


\section{In-house UV Sensor}

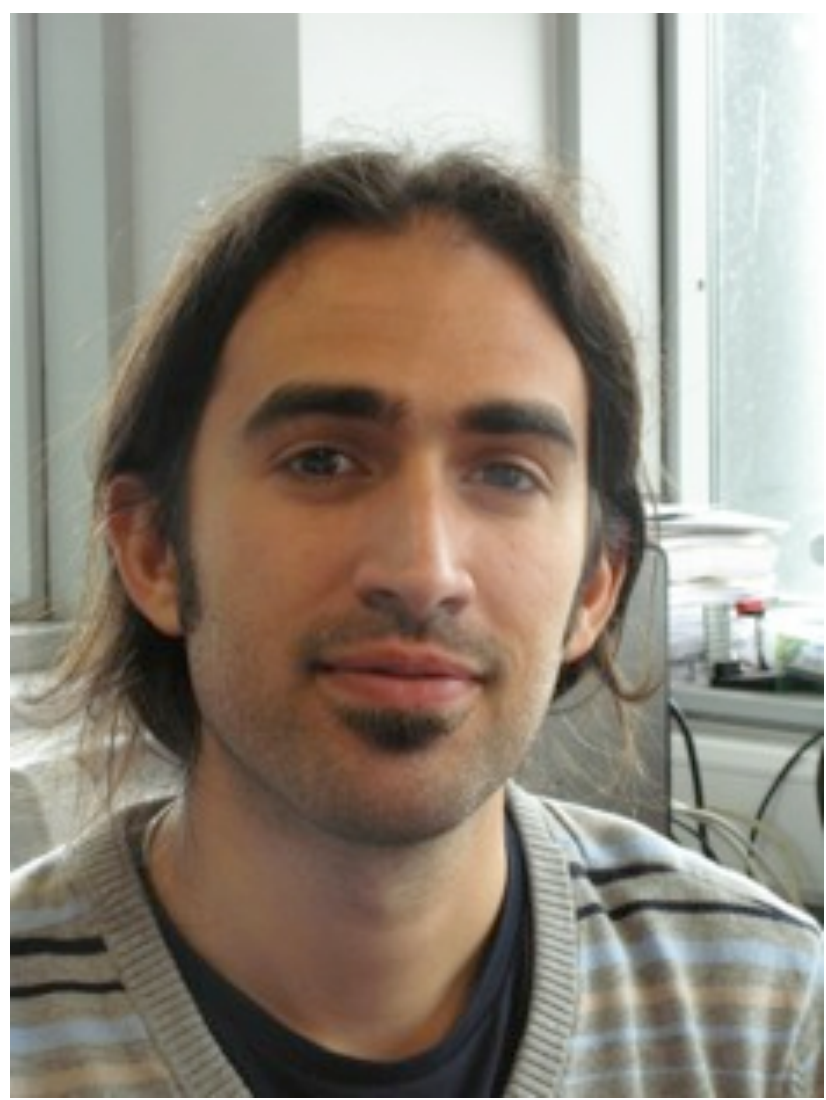

\section{2 hrs Sicily}

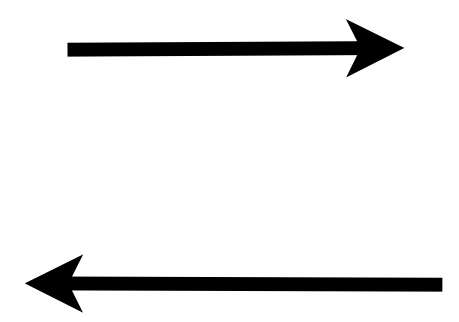

\section{Dublin}
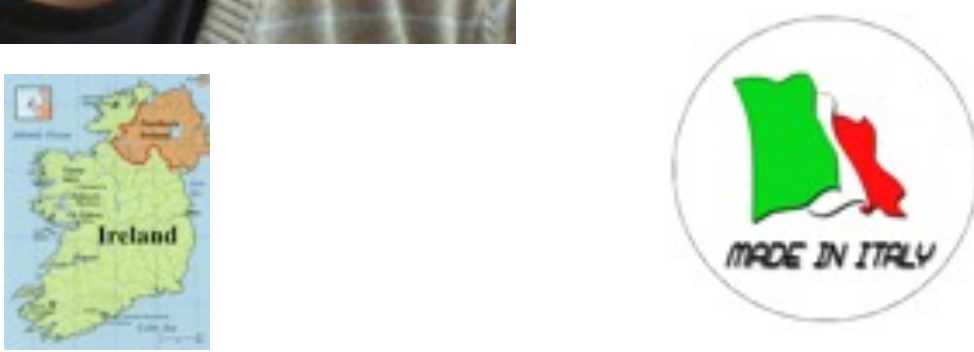
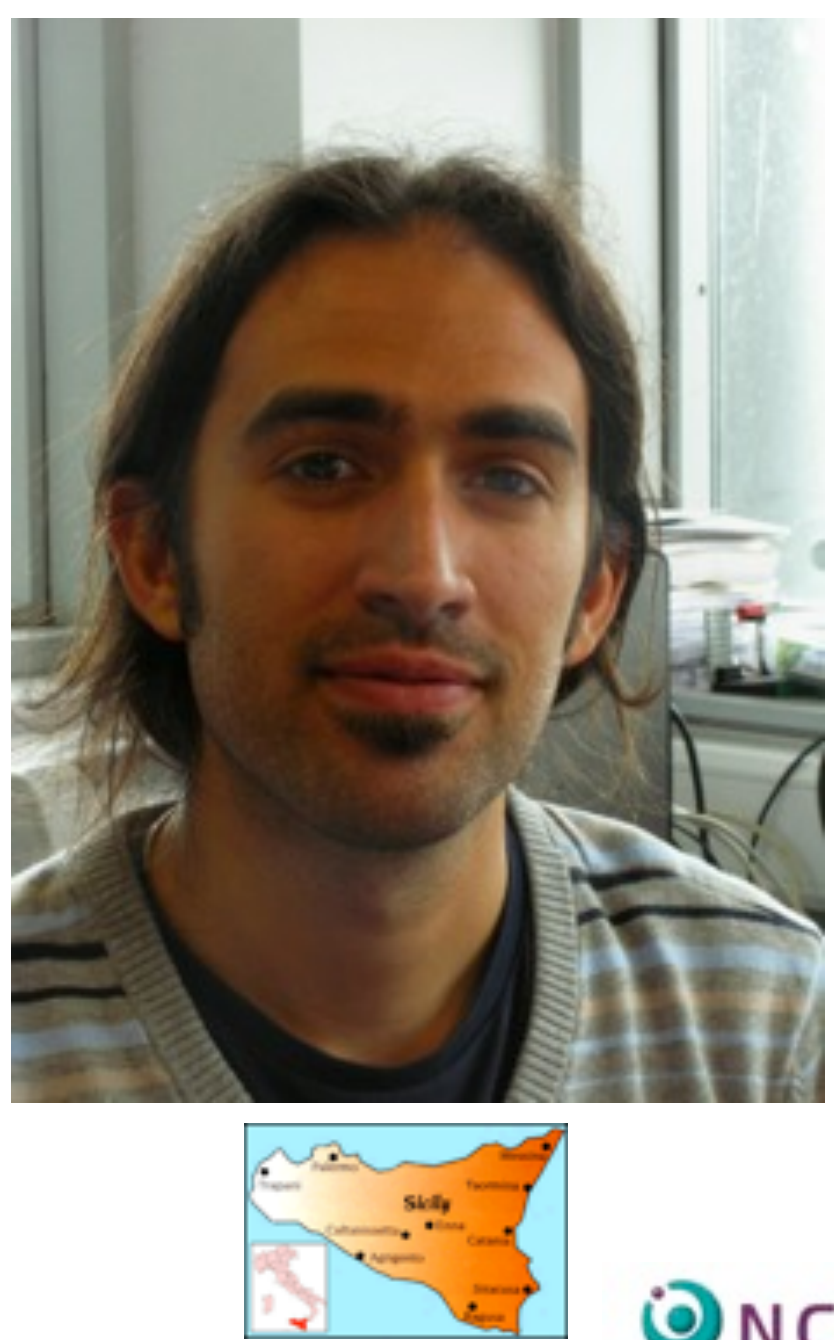

(i) NCSR 


\section{Current Wearable Sensors}

\section{PHYSICAL SENSORS}

Breath rate, heart rate, activity, posture, skin temperature... 


\section{Current Wearable Sensors}

\section{$\Delta$ \\ CLARITY

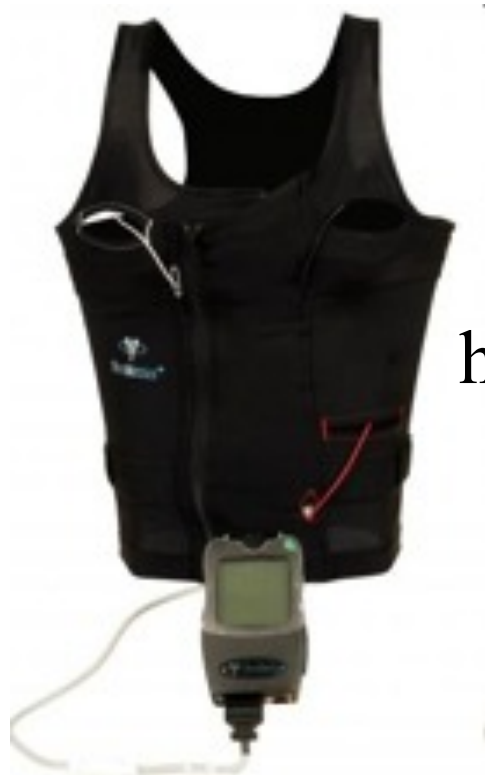

\section{PHYSICAL SENSORS}

Breath rate, heart rate, activity, posture, skin temperature...

TRAINTRAK ${ }^{\mathrm{TM}}$

heart rate, respiration rate, posture, activity, and GPS location

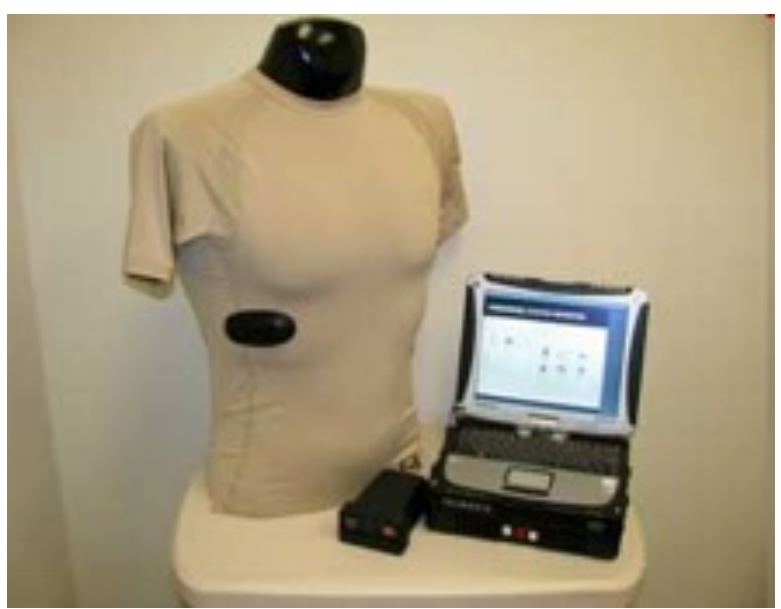

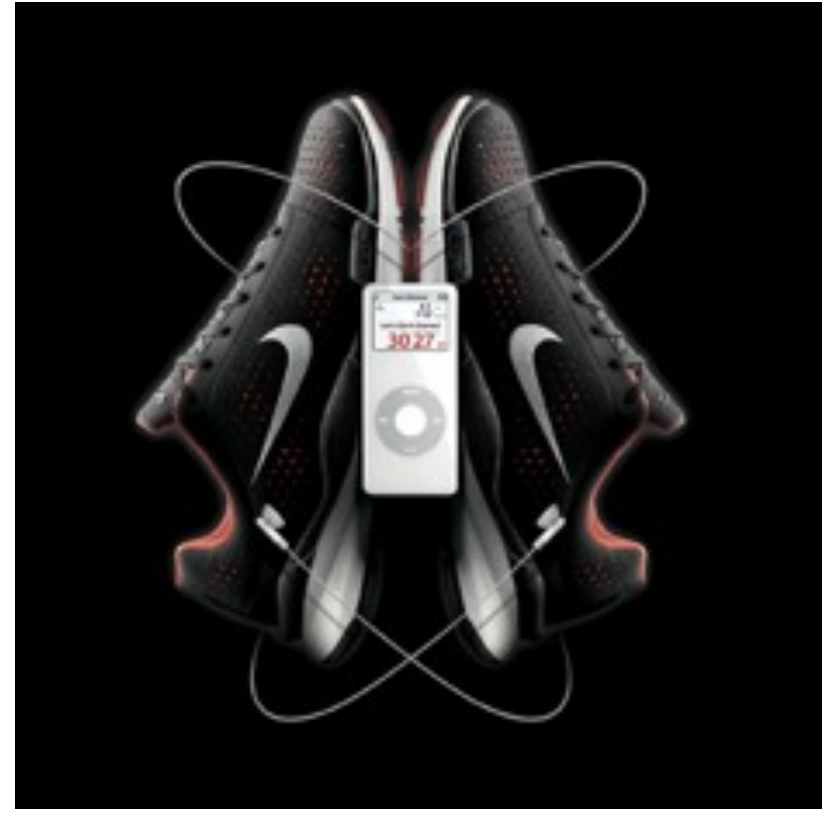

NIKE-APPLE iPOD SPORTS KIT 


\section{Current Wearable Sensors}

\section{Scosche myTrek sends workout vitals to your iPhone, starts shipping now for $\$ 130$ (video) \\ By Zach Hanig D pasted Atigg grh zon g:soPM}
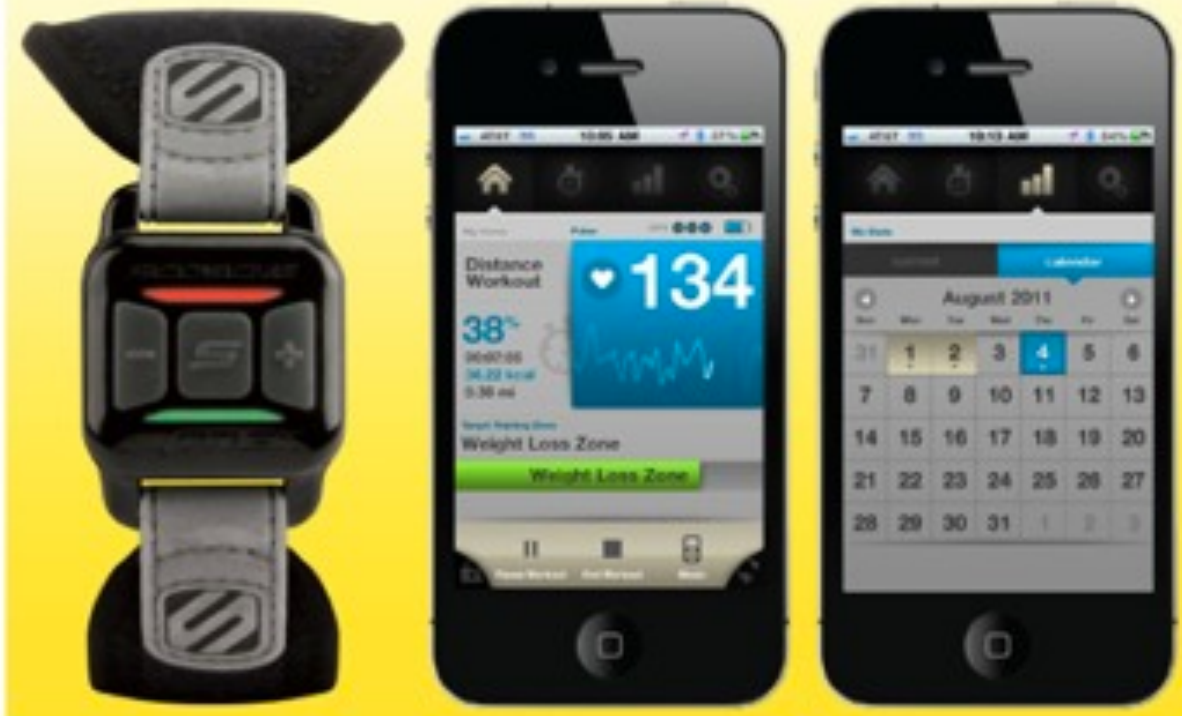

The myTREK utilizes two LEDs combined with a photo sensor to detect minute changes in the user's blood pressure to accurately measure pulse. A built-in accelerometer allows the myTREK to adjust for movement during exercise from the user's heartbeat allowing for an extremely accurate measurement of pulse and calories burned. 


\section{Current Wearable Sensors}

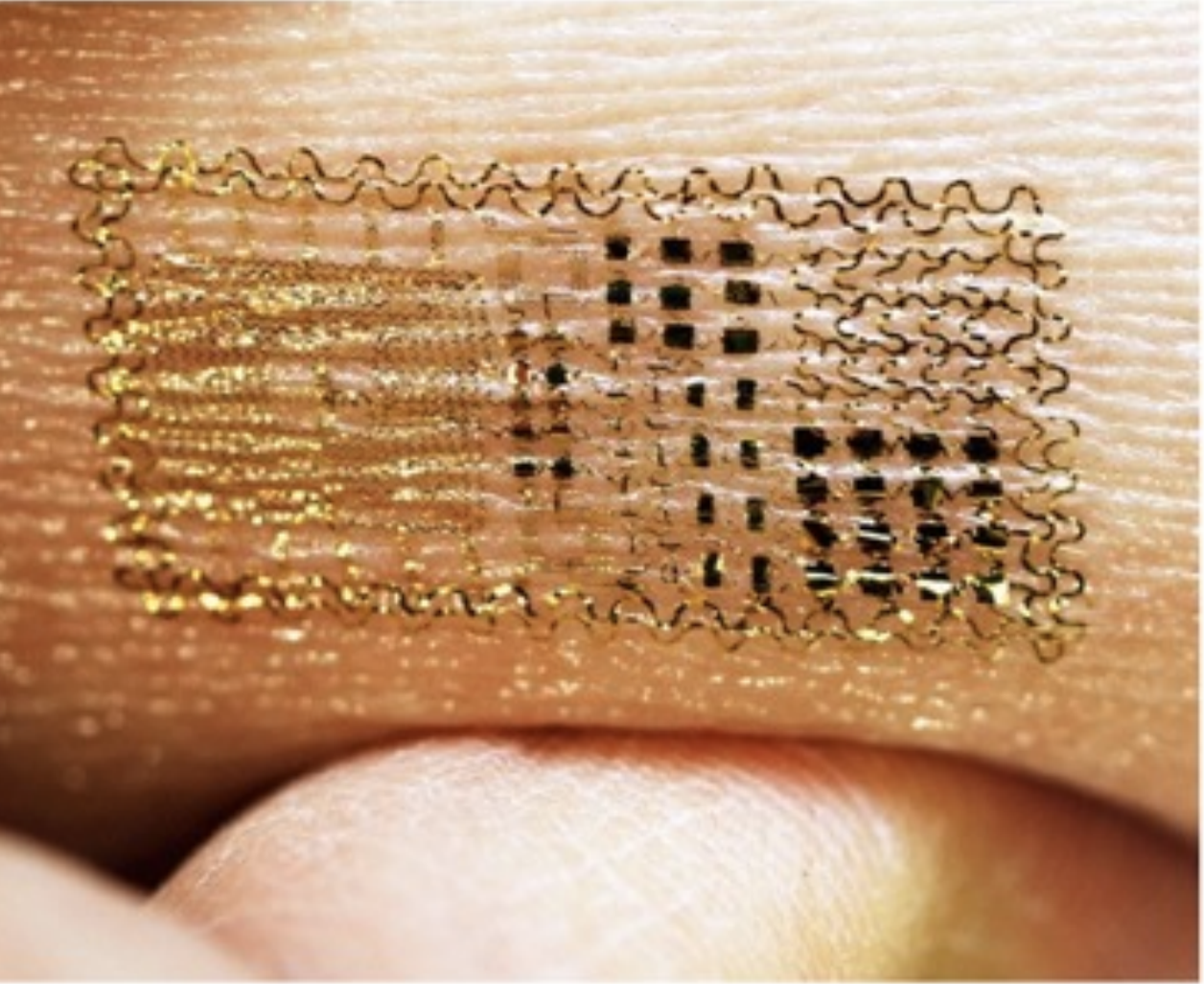

John Rogers@ @niversity of Illinois

$$
11 / 08 / 2011
$$

Ultra-thin, self-adhesive electronics device that can effectively measure data about the human heart, brain waves and muscle activity--all without the use of bulky equipment, conductive fluids or glues.

Link :http://www.nsf.gov/news/news summ.jsp?cntn id=121343\&org=NSF\&from=news

ONCSR 


\section{Current Wearable Sensors}

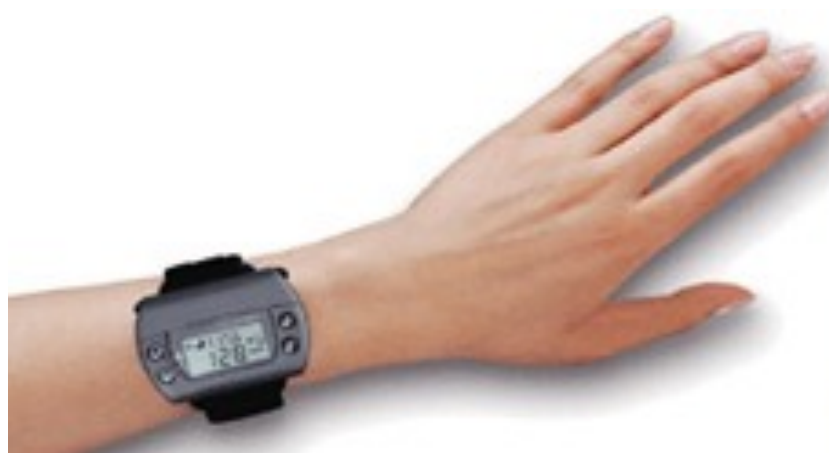

Glucowatch

Abbot Freestyle Navigator
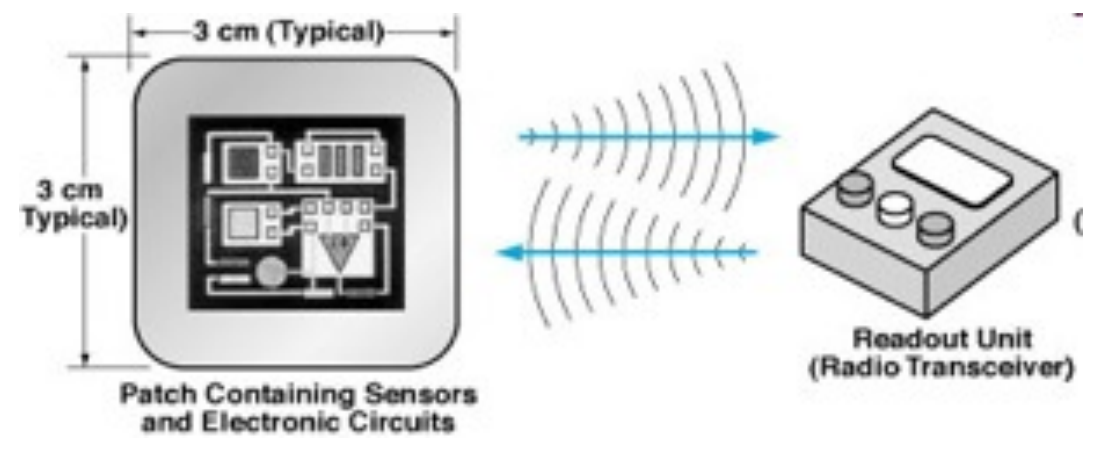

NASA: Wearable sensor patches

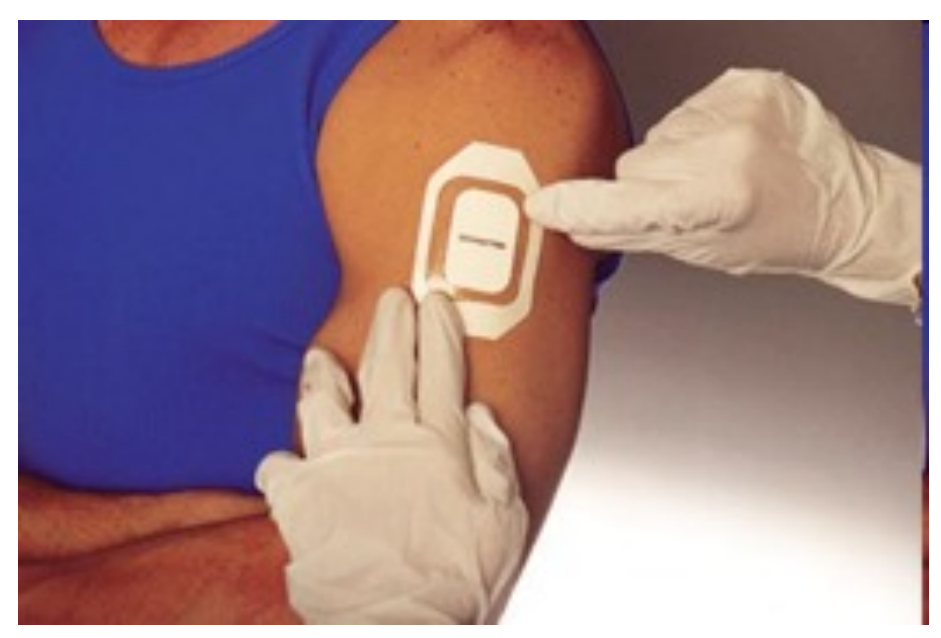

PharmChek Sweat Patch

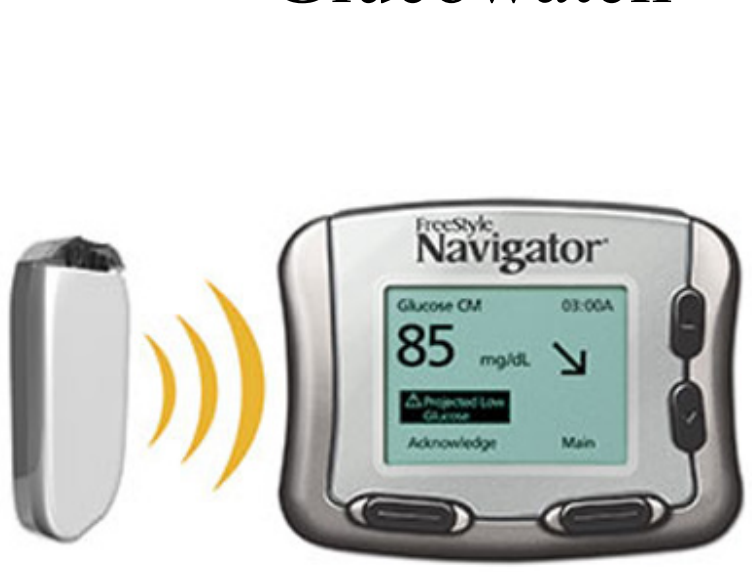

12 of 39

Thursday, 25 August 11 


\section{Current Wearable Sensors}

\section{$\Delta \nabla$ \\ CLARITY

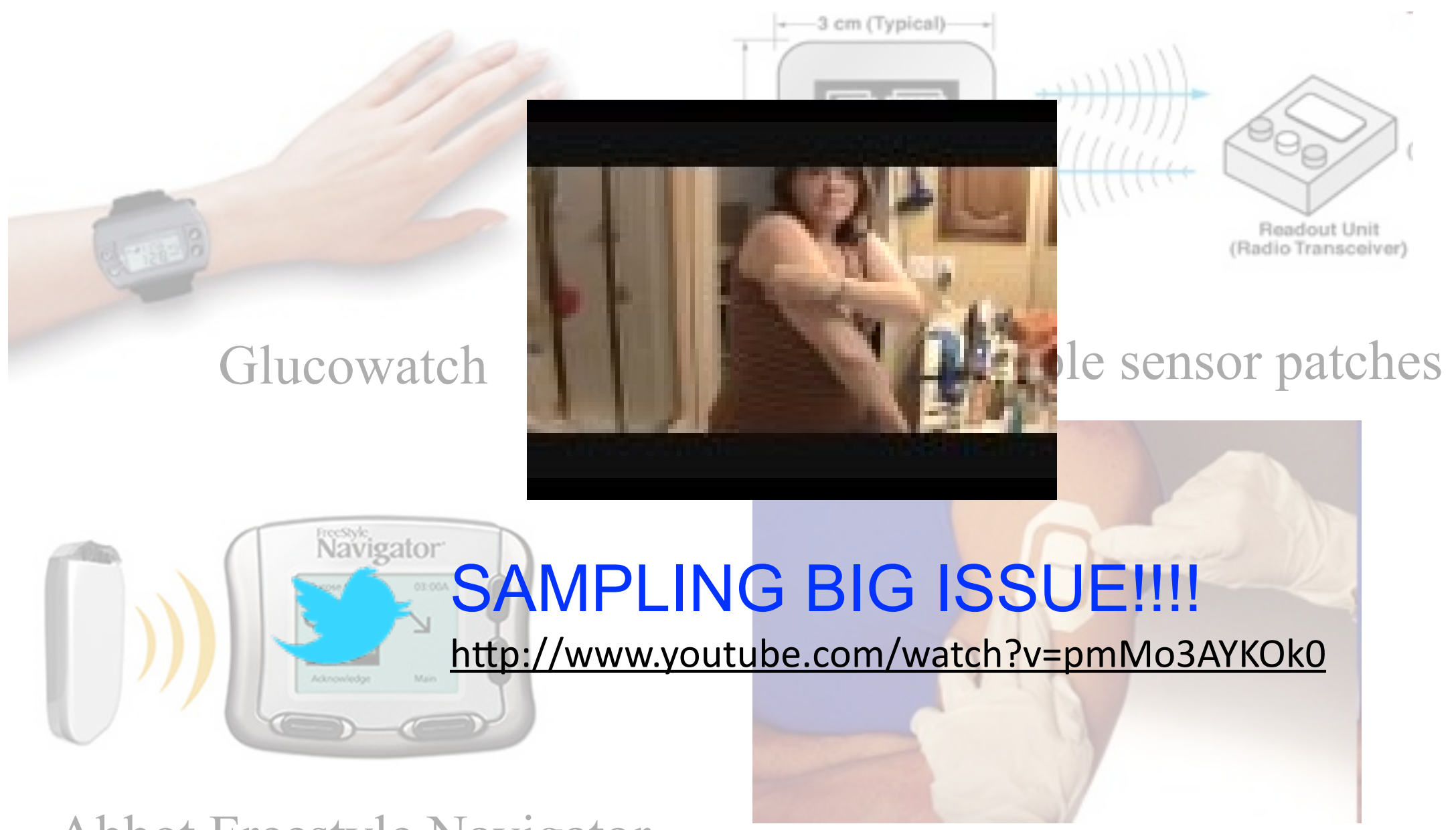

Abbot Freestyle Navigator

\section{PharmChek Sweat Patch}




\section{Wearable electrochemical Sensors}




\section{Wearable electrochemical Sensors}

\section{Why sweat?}

- The great advantage of analyzing sweat for health monitoring is that it is noninvasive, easily accessible, and it offers valuable physiological information

- The sweat test previously used for the diagnosis of cystic fibrosis (CF)

- This is a once-off test that is performed in newborns and the diagnosis is based on sodium and chloride concentration levels. 


\section{The BIOTEX project}

- BIOTEX was an EU-funded project that aimed to develop textile sensors to measure physiological parameters and the chemical composition of body fluids, with a particular interest in sweat.

- Wearable sensing system had been developed that integrates a textile-based fluid handling system for sample collection and transport with a number of sensors including sodium, conductivity, and $\mathrm{pH}$ sensors.

- It was possible to monitor a number of physiological parameters together with sweat composition in real time. 


\section{The BIOTEX project}

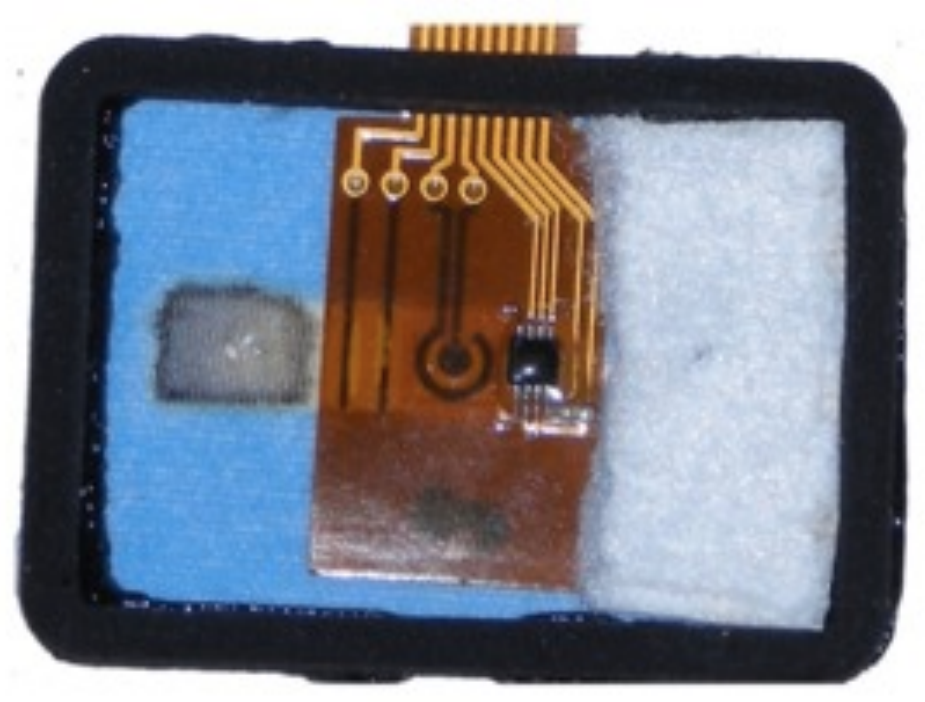

- Multiparametric patch containing $\mathrm{pH}$ indicator, conductivity, sodium, and temperature sensors. 


\section{The BIOTEX project}
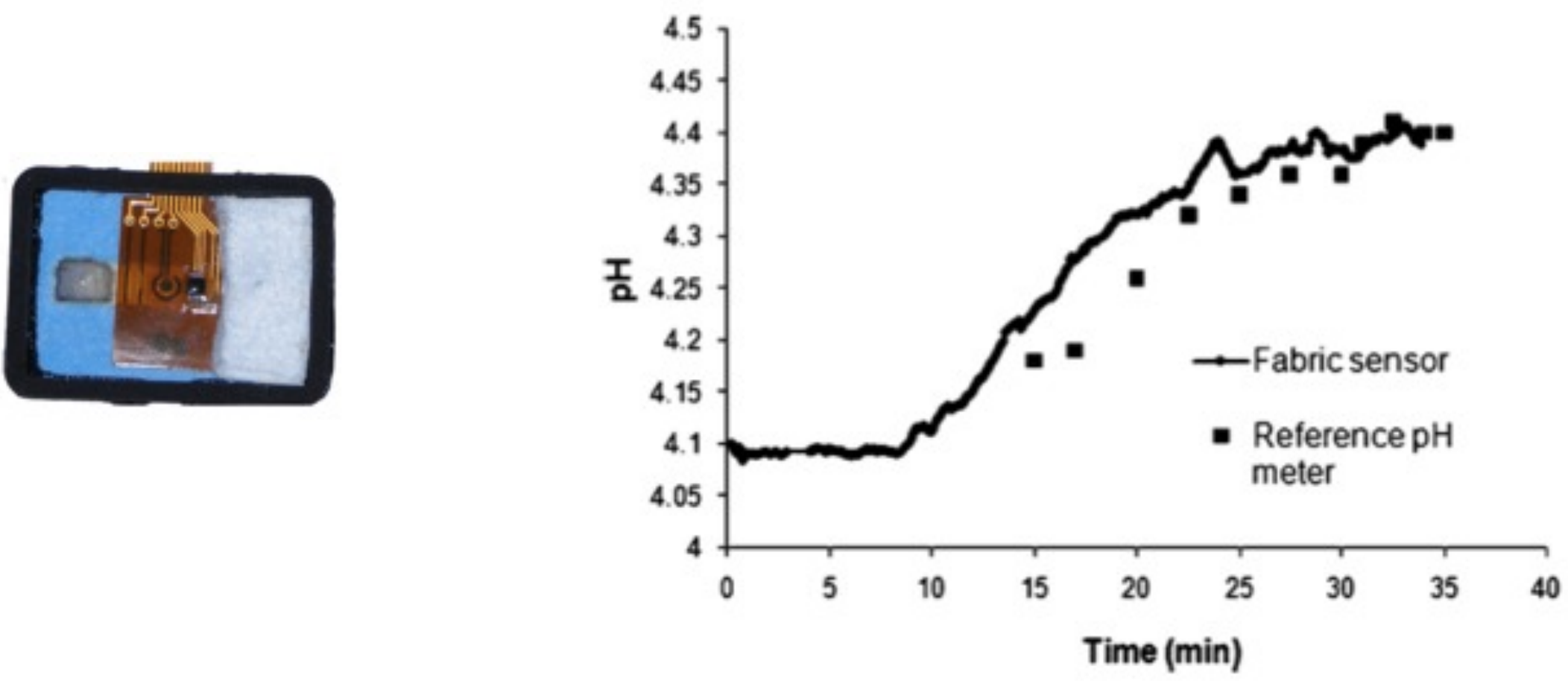


\section{The BIOTEX project}

- The textile pump has been designed in such a way that it can successfully collect sweat from human subjects during exercise.

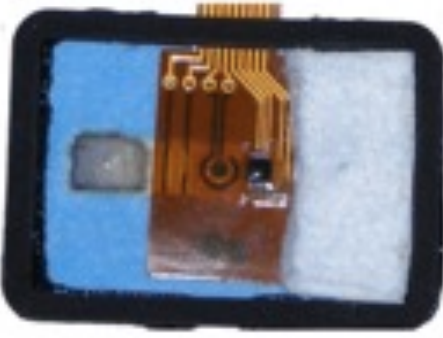

- Sweat is analyzed by $\mathrm{pH}$, sodium, and conductivity sensors and stores the sample in an absorbent in such a way as to allow for a continuous flow of fresh sweat.

- The ability to measure changes in sweat electrolyte concentrations can assist people in choosing the correct level of hydration and avoid the need for medical intervention. 


\section{The BIOTEX project}

- The textile pump has been designed in such a way that it can successfully collect sweat from human subjects during exercise.

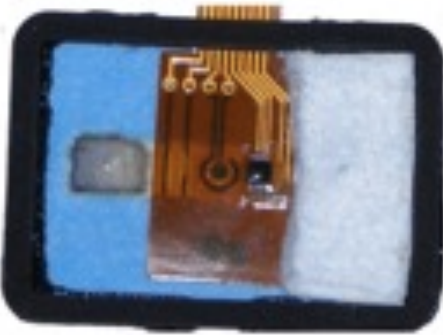

- Sweat is analyzed by $\mathrm{pH}$, sodium, and conductivity sensors and stores the sample in an absorbent in such a way as to allow for a continuous flow of fresh sweat.

\section{http://www.biotex-eu.com/}




\section{lonic Liquids: A brief introduction}

\section{What is an Ionic Liquid (IL)?}

- According to current convention, a salt melting below the normal boiling point of water is known as an "ionic liquid" 


\section{lonic Liquids: A brief introduction}

\section{What is an Ionic Liquid (IL)?}

- According to current convention, a salt melting below the normal boiling point of water is known as an "ionic liquid"

- The first IL was reported almost a century ago by Walden ${ }^{[5]}$, who protonated ethylamine with nitric acid to yield ethylammonium nitrate 


\section{Ionic Liquids: A brief introduction}

\section{What is an Ionic Liquid (IL)?}

- According to current convention, a salt melting below the normal boiling point of water is known as an "ionic liquid"

- The first IL was reported almost a century ago by Walden ${ }^{[5]}$, who protonated ethylamine with nitric acid to yield ethylammonium nitrate

- The number of potential anion-cation combinations available reputedly equate to one trillion $\left(10^{12}\right)$ different ILs $^{[6]}$

[5] P. Walden, Bull. Acad. Sci. St. Petersburg, 1914, 405.

[6] R. D. Rogers and K. R. Seddon, Ionic Liquids as Green Solvents: Progress and Prospects, 


\section{Ionic Liquids: A brief introduction}

\section{What is an Ionic Liquid (IL)?}

De-localized charges

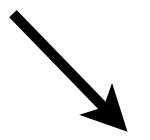

Asymmetric ion shape

(poor packing)

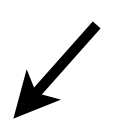

Melting point below $100^{\circ} \mathrm{C}$ 


\section{lonic Liquids: A brief introduction}

\section{What is an Ionic Liquid (IL)?}

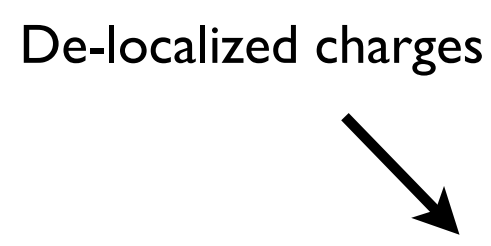

Asymmetric ion shape

Melting point below $100^{\circ} \mathrm{C}$

Typical ions to form ionic liquids

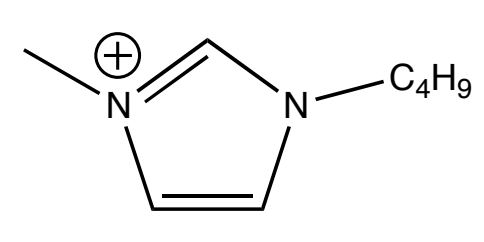

Hydrophilic

$\mathrm{Tg}-81^{\circ} \mathrm{C}$ only
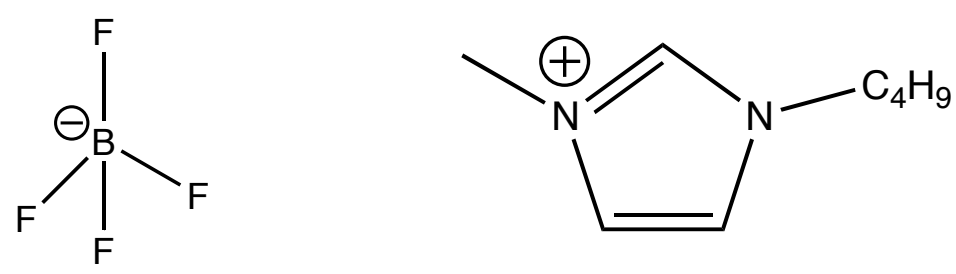

Hydrophobic M.P. of $6.4^{\circ} \mathrm{C}$

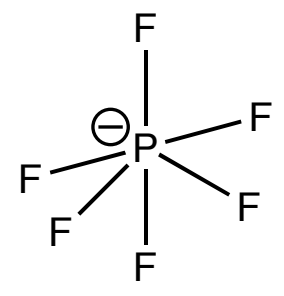

ONCSR 


\section{lonic Liquids: A brief introduction}

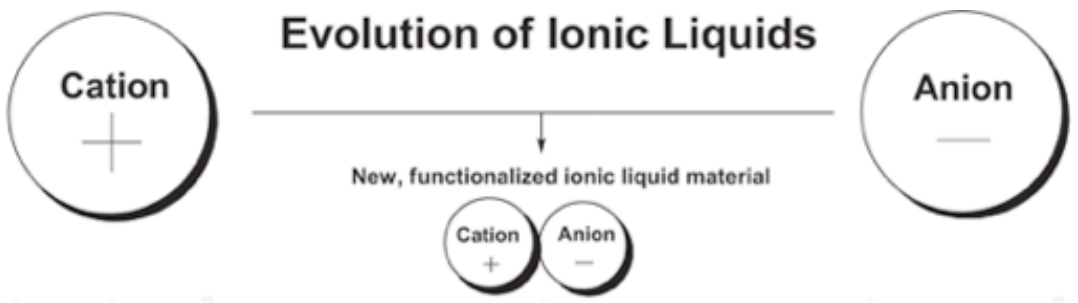

\section{Generation 1:}

ILs with unique tunable physical properties

\section{Physical property}

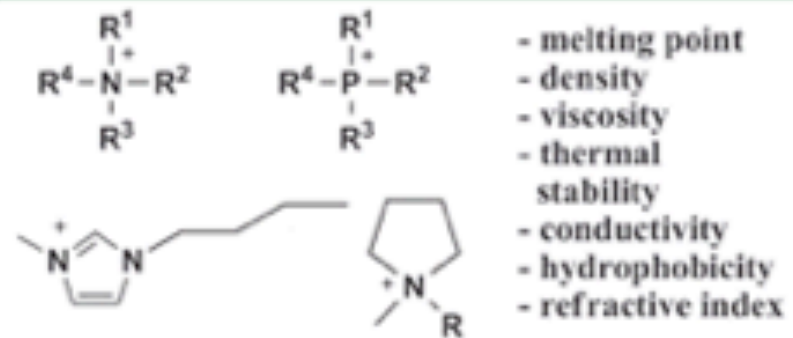<smiles>CCCCn1cc[n+](C)c1</smiles>

lower melting point / hydrophobicity

$$
\mathrm{C}_{6} \mathrm{H}_{14}-\underset{\mathrm{C}_{6} \mathrm{H}_{13}}{\stackrel{\mathrm{P}}{\mathrm{l}}-\mathrm{C}_{14} \mathrm{H}_{29}} \quad \mathrm{NC} 、 \mathrm{~N}_{\mathrm{C}_{6} \mathrm{H}_{14}}, \mathrm{CN}
$$

hydrophobicity / lower viscosity

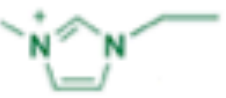

CI

high thermal stability / hydrophilicity
Physical property

$$
\begin{aligned}
& \text { - melting point } \\
& \text { - density } \\
& \text { - viscosity } \\
& \text { - thermal } \\
& \text { stability } \\
& \text { - conductivity } \\
& \text { - hydrophobicity } \\
& \text { - refractive index }
\end{aligned}
$$

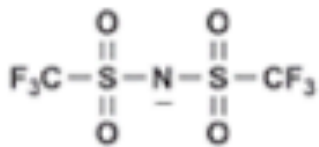

$$
\begin{aligned}
& \mathrm{Cl}^{-} \\
& \text {NC. }{ }_{\mathrm{N}}^{-\mathrm{CN}} \mathrm{BF}_{4}^{-} \\
& \mathrm{HO}-\stackrel{\mathrm{O}}{\mathrm{O}} \underset{\mathrm{O}}{\mathrm{O}}-\mathrm{O}^{-} \\
& \sim \mathrm{s}^{\prime \prime} \mathrm{s}^{\circ} \\
& \text { o } \\
& \mathrm{O}-\underset{\mathrm{s}}{\mathrm{II}}-\mathrm{O}
\end{aligned}
$$




\section{lonic Liquids: A brief introduction}

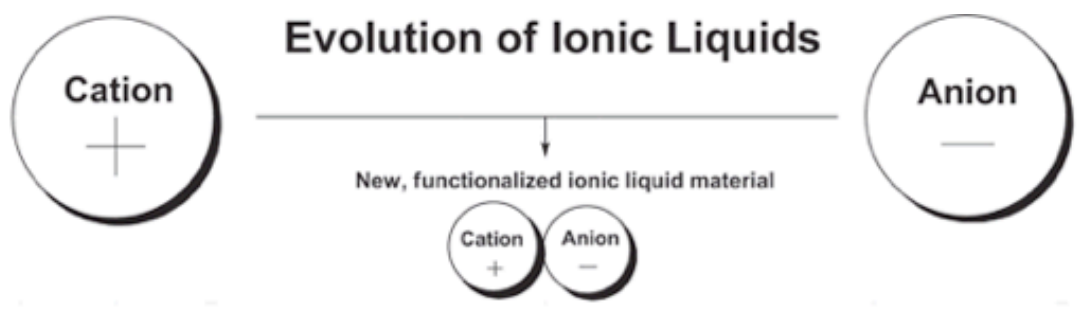

Generation 2:

ILs with targeted chemical properties combined with chosen physical properties

\section{Chemical property}

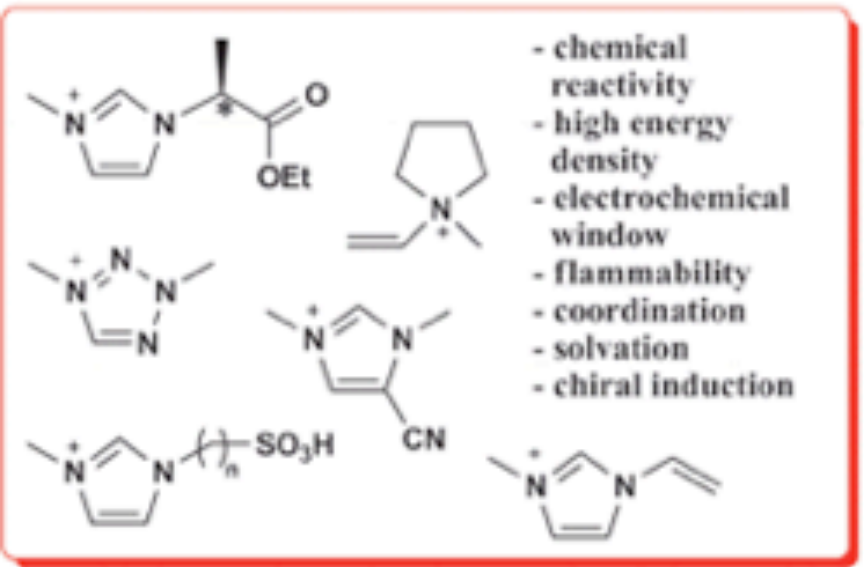

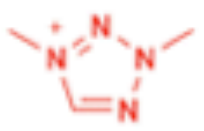

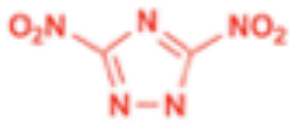

energy density / oxygen balance

$$
\mathrm{N}_{\mathrm{N}}
$$

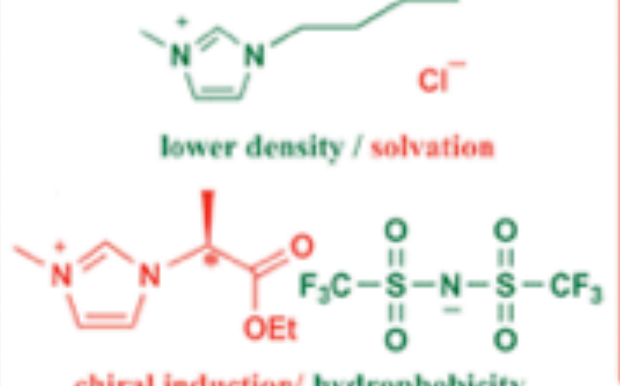

chiral induction/ hydrophobicity

\section{Chemical property}

- high energy
density
- electrochemical
window
- flammability
- oxygen balance
- UV blocker
- chiral iaduction
- solvation
$\mathrm{Cl}^{-}$




\section{lonic Liquids: A brief introduction}

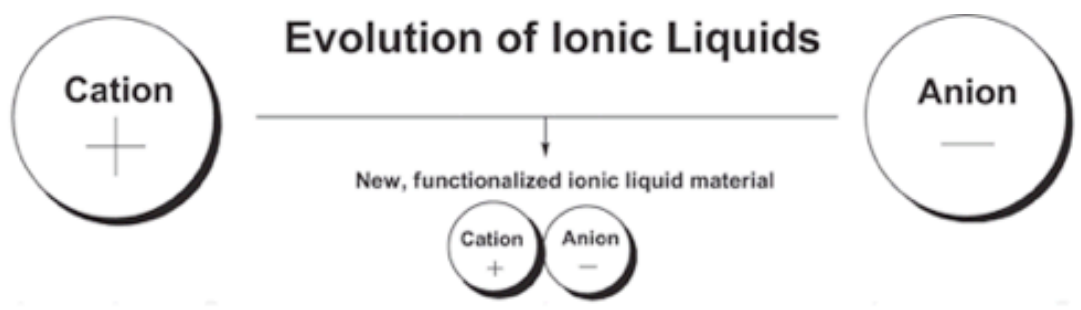

Generation 3:

ILs with targeted biological properties combined with chosen physical and chemical properties

Biological property
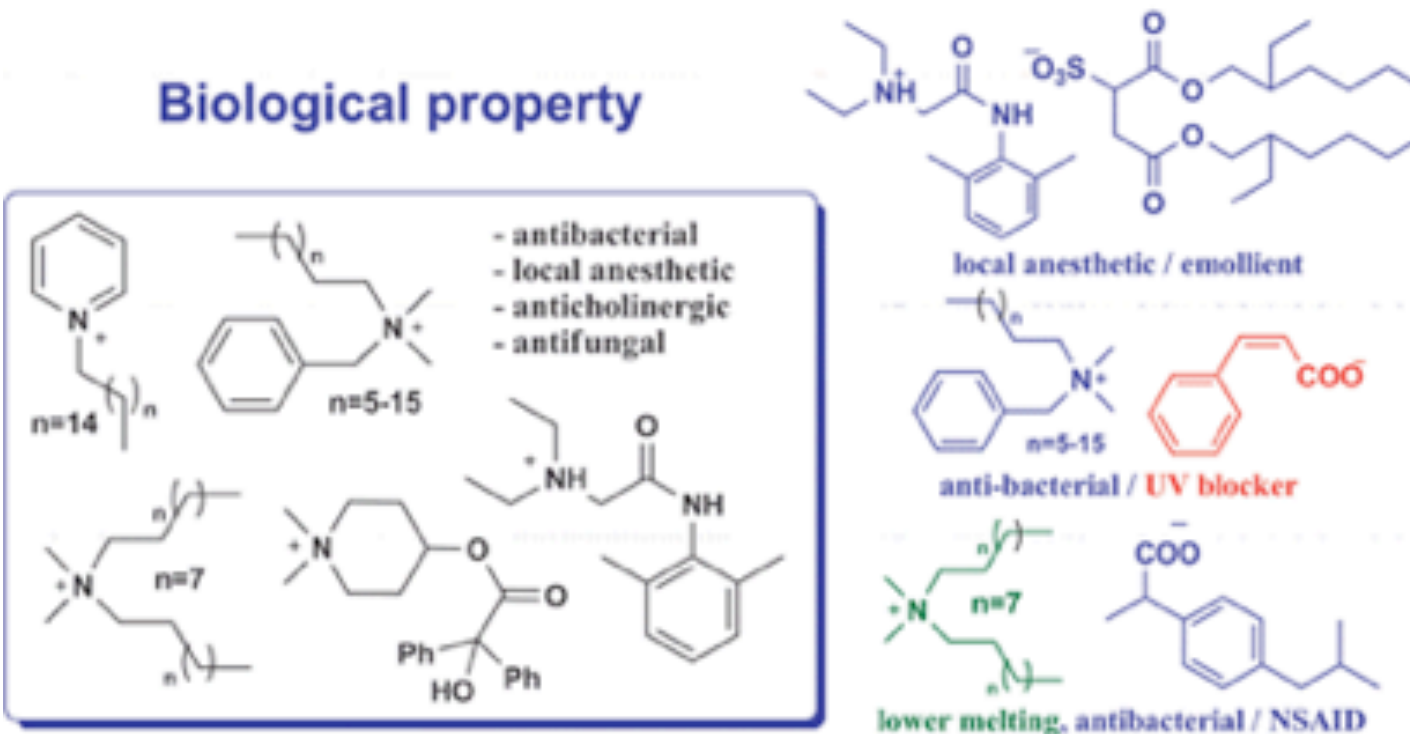

lower melting, antibacterial / NSAID

\section{Biological property}

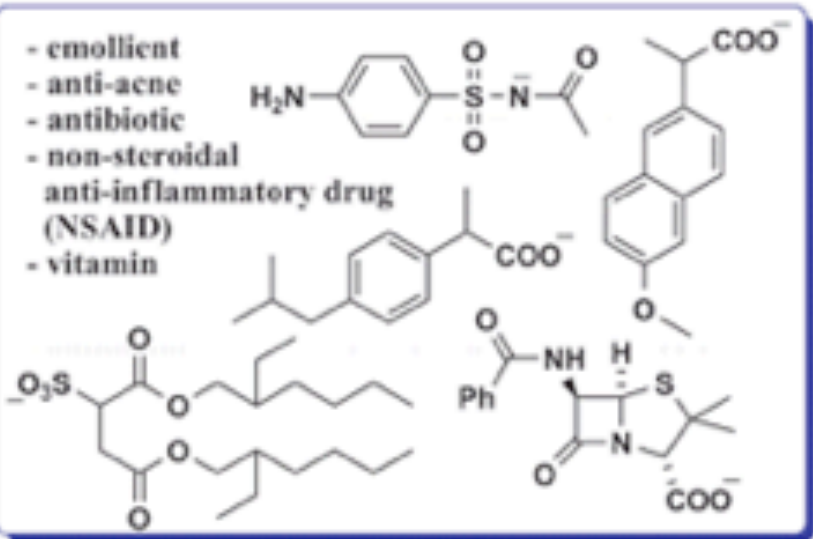

[7] W. L. Hough, M. Smiglak, H. Rodriguez, R. P. Swatloski, S. K. Spear, D. T. Daly, J. Pernak,

J. E. Grisel, R. D. Carliss, M. D. Soutullo, J. H. Davis and R. D. Rogers, New J. Chem., 2007, 31, 1429-1436. 


\section{lonic Liquids: A brief introduction}

Subsets of ILs

- Phosphonium based ILs

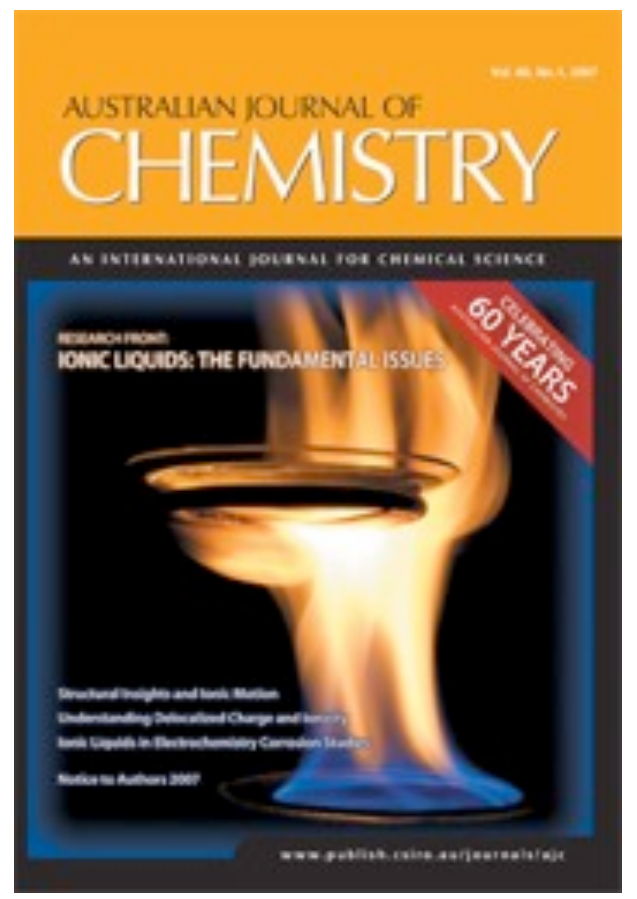

- Bio compatible ILs

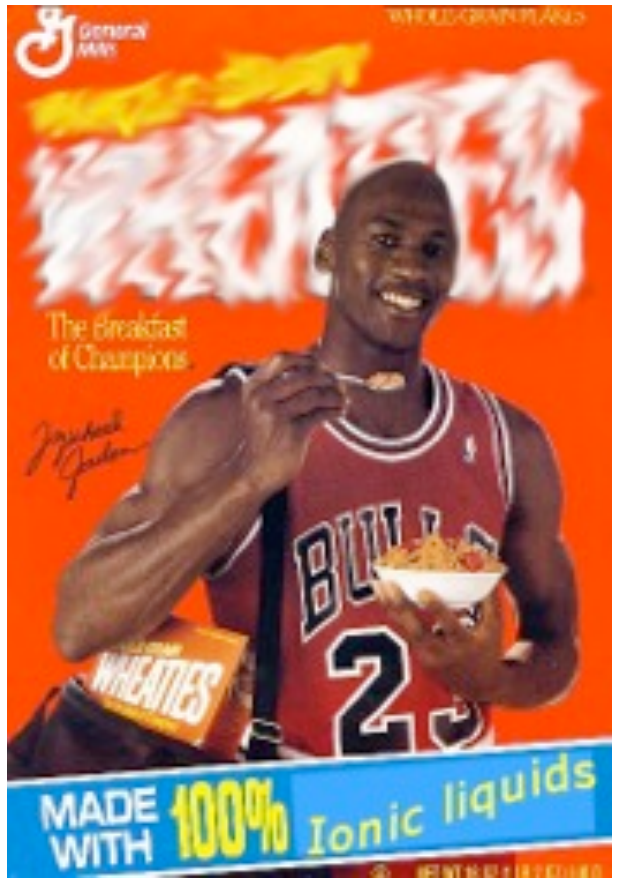




\section{lonic Liquids: A brief introduction}

- Cytec $^{\mathrm{R}}$ routinely produces tetraalkylphosphonium halides

such as the ionic liquid trihexyl-tetradecyl phosphonium

chloride

- Phosphonium based ILs

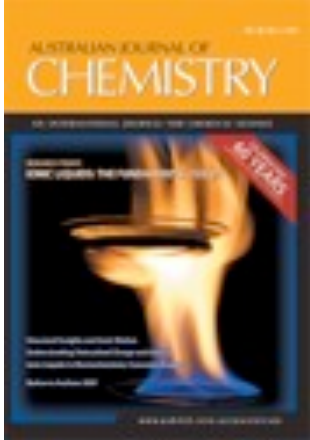




\section{lonic Liquids: A brief introduction}

- Cytec $^{\mathrm{R}}$ routinely produces tetraalkylphosphonium halides

such as the ionic liquid trihexyl-tetradecyl phosphonium

chloride

- Phosphonium based ILs

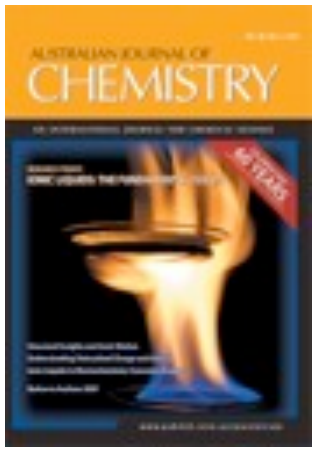

- Phosphonium ILs offer, in some cases, several advantages over other types of ILs, including, higher thermal stability, lower viscosity, and higher stability in strongly basic or strongly reducing conditions.

- Historically these compounds have been used as biocides ${ }^{[8]}$ and phase transfer catalysts ${ }^{[9]}$ 


\section{Ionic Liquids: A brief introduction}

- Phosphonium based ILs<smiles>[O-][P-](Cl)(c1ccccc1)c1ccccc1</smiles>

Trihexyl-tetradecyl phosphonium chloride,

Liquid at room temperature

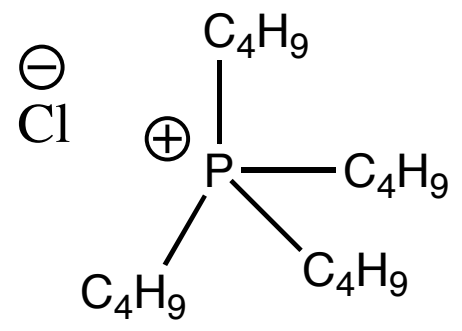

Tetrabutyl phosphonium chloride

M.P $67^{\circ} \mathrm{C}$

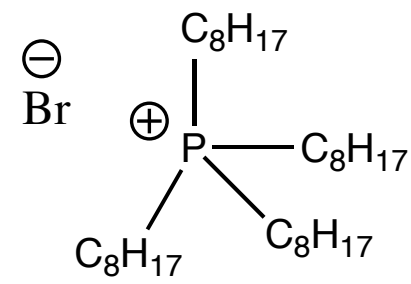

Tetraoctyl phosphonium bromide

M.P $45^{\circ} \mathrm{C}$ 


\section{lonic Liquids: A brief introduction}

\section{Excellent Review}

K. J. Fraser and D. R. MacFarlane, Aust. J. Chem., 2009, 62, 309-321.
Phosphonium-Based lonic Liquids An Overview

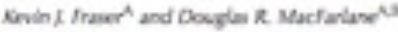

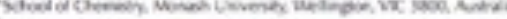

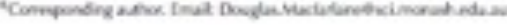

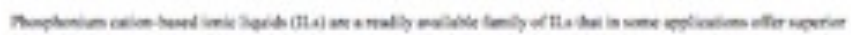

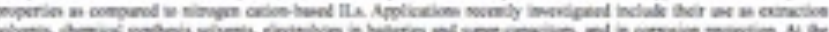

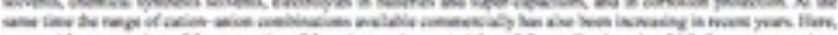

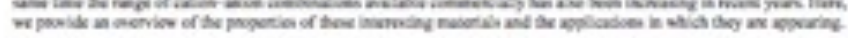

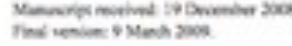

Intmoturtion

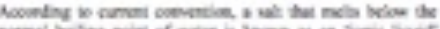
Tien he

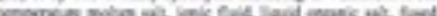

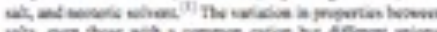

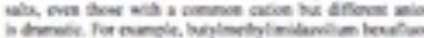

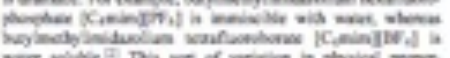

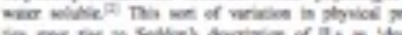

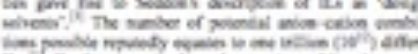

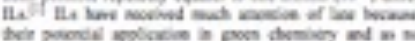

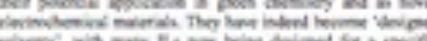

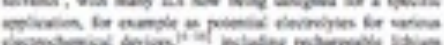

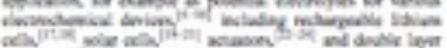

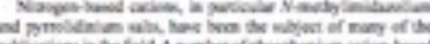
U.

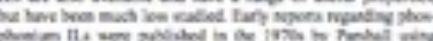

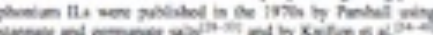

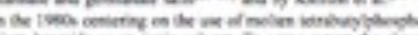

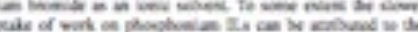

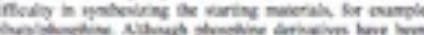

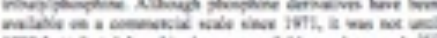

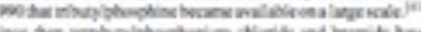

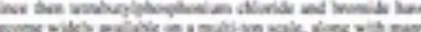

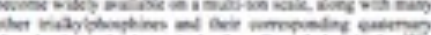

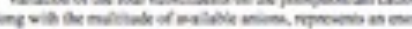

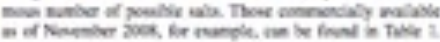

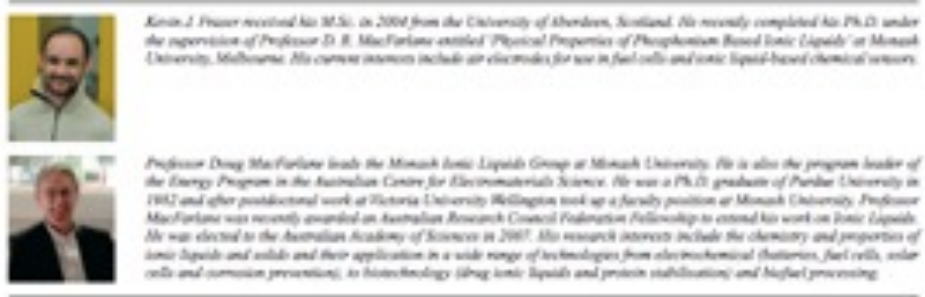




\section{lonic Liquids: A brief introduction}

\section{Bio compatible ILs}

- In an attempt to steer away from fluorous anions, a communication by Carter et al. ${ }^{[11]}$ opened up a new field in the Ionic liquid world.

- The use of common sweeteners such as saccharin and acesulfamate were used in the formation of new ionic liquids. ${ }^{[11]}$

- These anions, in their alkali metal salt form, are widely used in foodstuffs and non-nutritive sweeteners 


\section{lonic Liquids: A brief introduction}
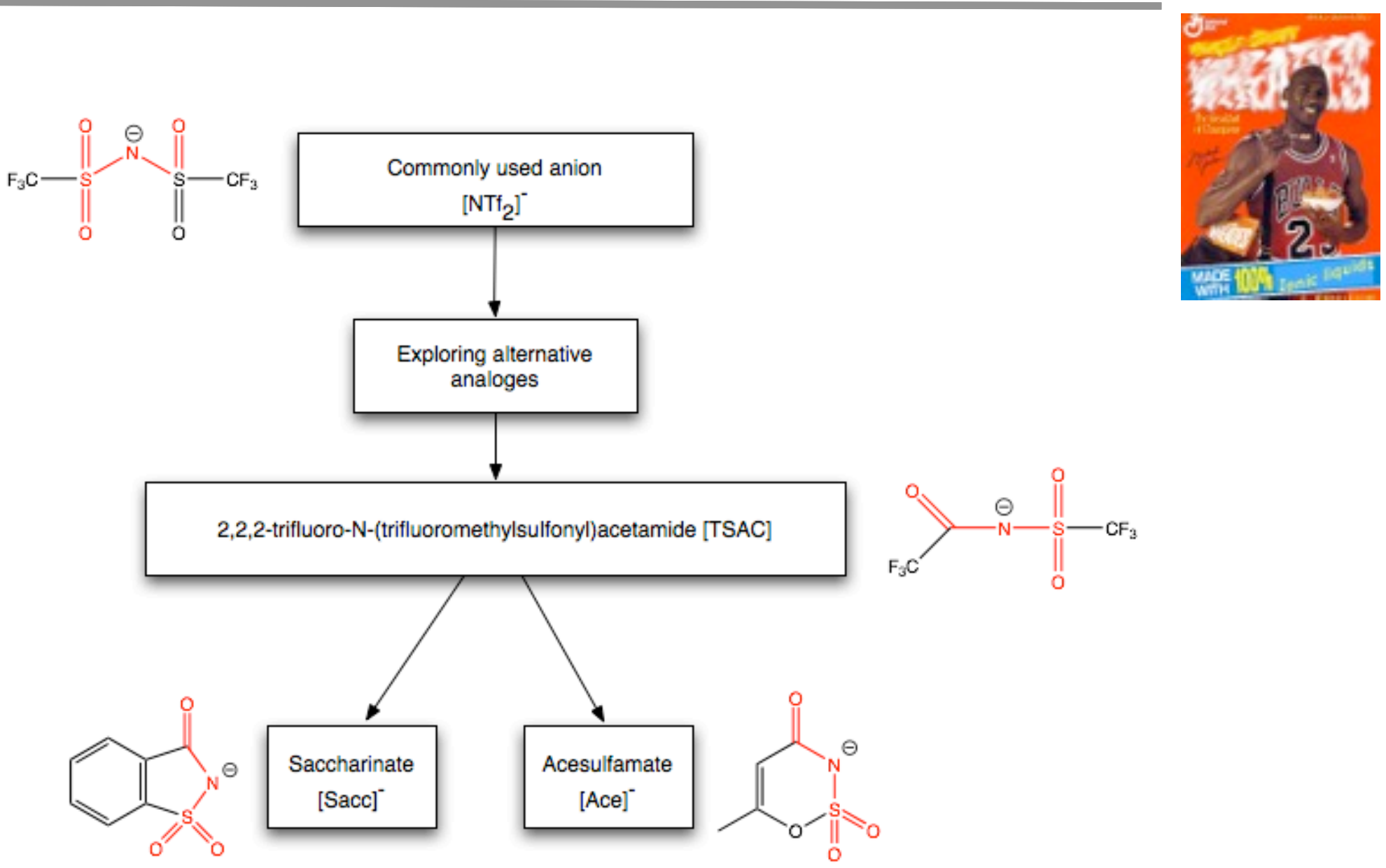

ONCSR 


\section{lonic Liquids: A brief introduction}

- Ionic liquids (ILs) have evolved as a new type of non-aqueous solvents for biocatalysis, mainly due to their unique and tunable physical properties ${ }^{[12]}$

Factors that affect Enzyme activity in ILs 


\section{lonic Liquids: A brief introduction}

- Ionic liquids (ILs) have evolved as a new type of non-aqueous solvents for biocatalysis, mainly due to their unique and tunable physical properties ${ }^{[12]}$

Factors that affect Enzyme activity in ILs

IL polarity Hydrogen bonding bascicity

Viscosity

Ion kosmotropicity

Enzyme dissolution 


\section{lonic Liquids: A brief introduction}

Through smart design enzyme stability can be greatly enhanced
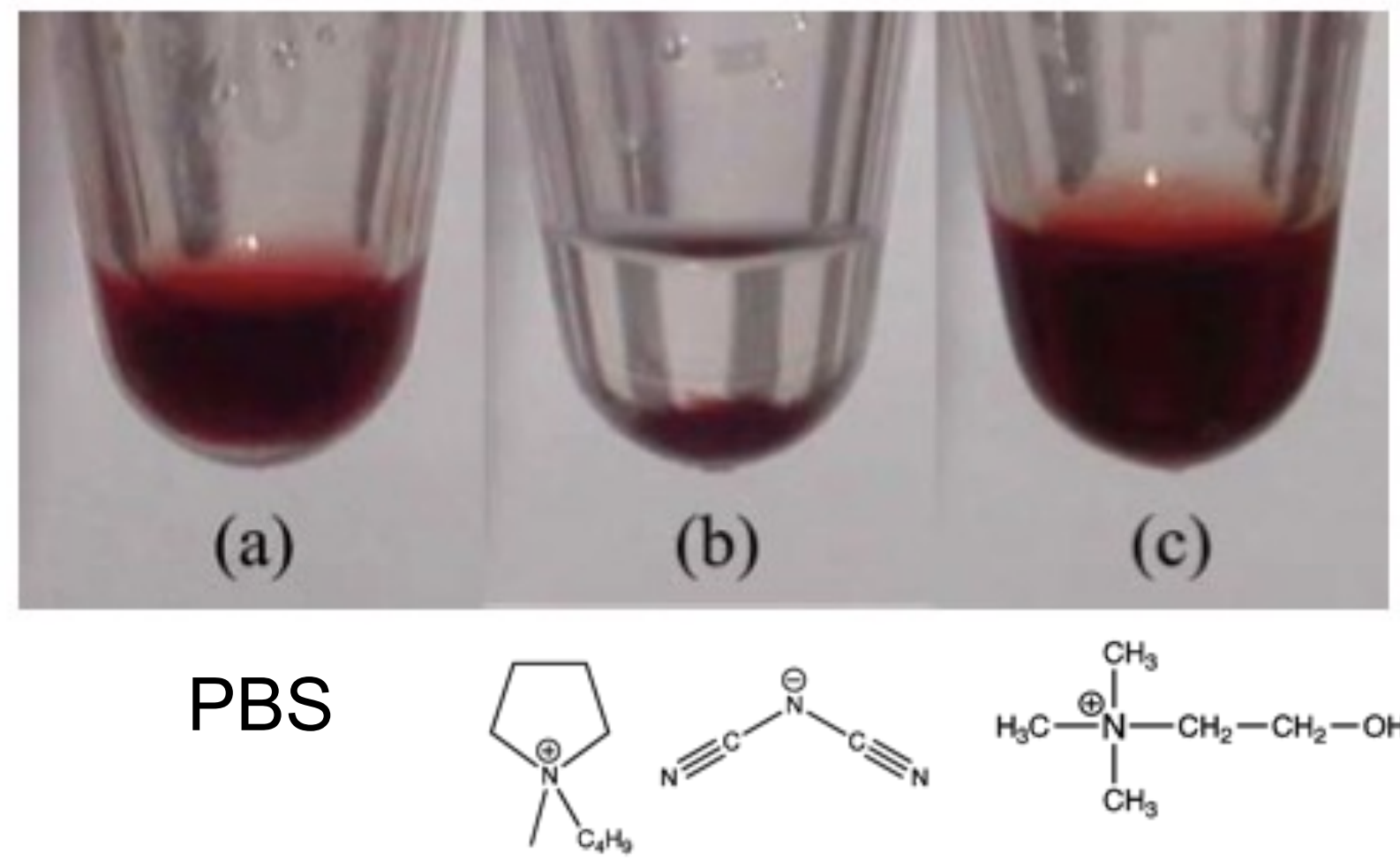<smiles>C[N+](C)(C)CCO</smiles><smiles>O=P([O-])(O)O</smiles> 


\section{lonic Liquids: A brief introduction}

Through smart design enzyme stability can be greatly enhanced

- Enhanced solubility of cytochrome c.

- dhp anion provided both a proton activity similar to that in neutral water as well as hydrogen bonding donor and acceptor sites.

- Choline DHP should enzyme stability up to 130 oC 


\section{Ideas Tree for Ionic liquids}

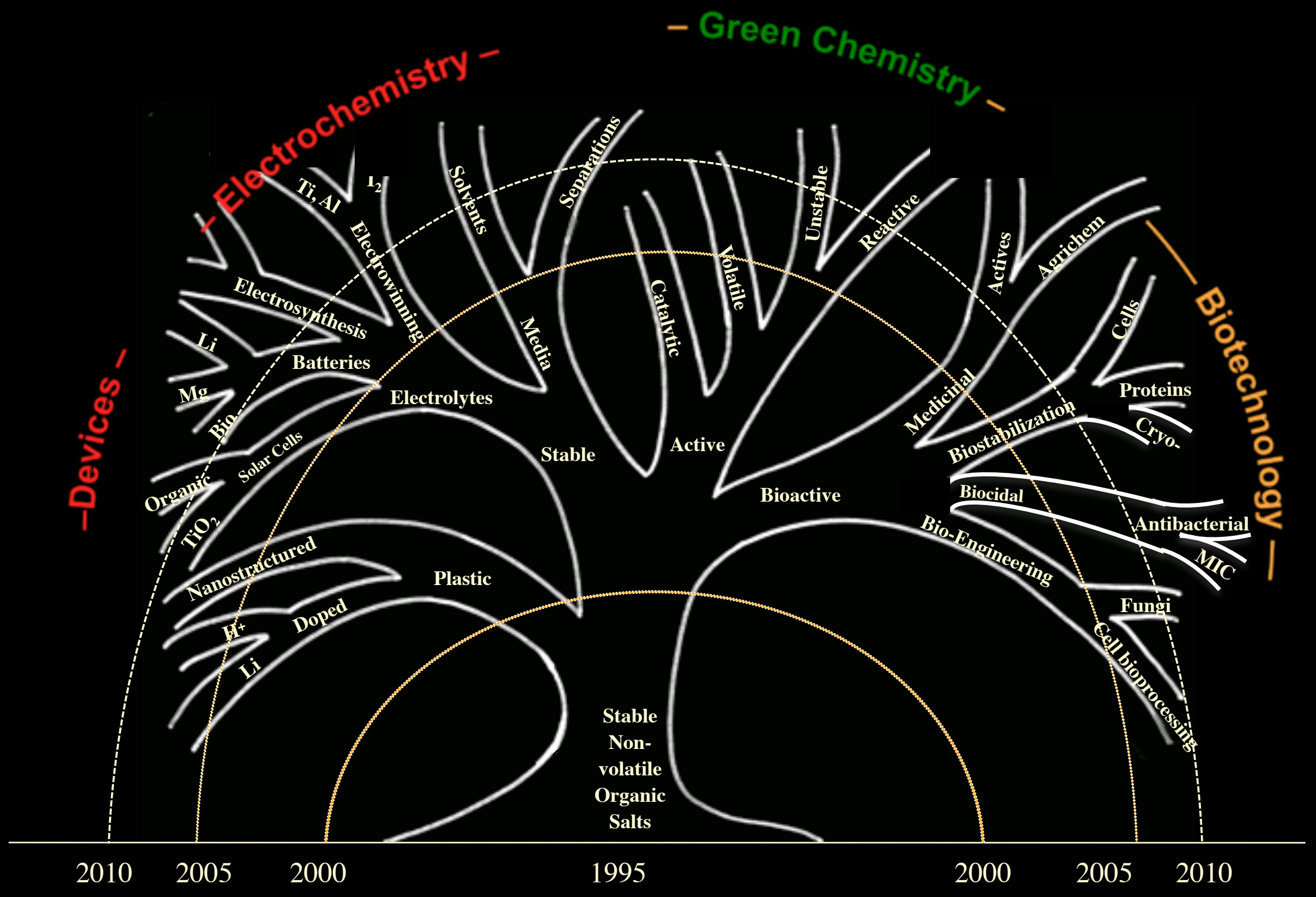

http://www.chem.monash.edu.au/ionicliquids/ 


\section{Sensing Platform: lonic liquids}

- Point-of-care (POC) glucose biosensors play an important role in the management of blood sugar levels in patients with diabetes.

- One of the most commonly used enzymes in glucose biosensors is Glucose Oxidase (GOx).

- Amperometric biosensors employing IL's have been reported previously, for example, $\left(\left[\mathrm{C}_{4} \mathrm{mIm}\right]\left[\mathrm{BF}_{4}\right]\right)$ has been used as a mediator in a electrochemical $\mathrm{H}_{2} \mathrm{O}_{2}$ biosensor ${ }^{[14]}$. 


\section{Sensing Platform: lonic liquids}

- This work investigates colorimetric and electrochemical methods of glucose detection by combining the enzyme's specificity, with the unique characteristics of IL's and either a chromogen (o-Dianisidine) or electrochemical mediator (ferrocene) to enhance the detection.

- This interest is driven by the need to find molecular environments in which enzymes are highly stabilized while retaining redox activity. 


\section{Sensing Platform: Ionic liquids}

- Ionic liquids used in this study include $\left[\mathrm{C}_{2} \mathrm{mIm}\right]\left[\mathrm{EtSO}_{4}\right],\left[\mathrm{P}_{6,6,6,14}\right][\mathrm{Cl}]$, $\left[\mathrm{P}_{6,6,6,14}\right][\mathrm{dca}]$ and $\left[\mathrm{P}_{6,6,6,14}\right]\left[\mathrm{NTf}_{2}\right]$

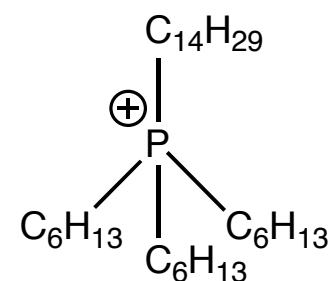

$\left[\mathrm{P}_{6,6,6,14}\right]^{+}$

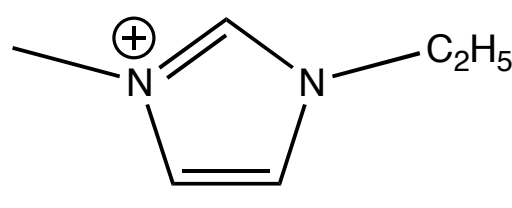

$\left[\mathrm{C}_{2} \mathrm{mIm}\right]^{+}$

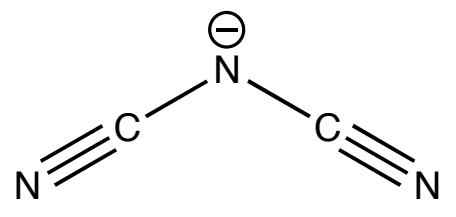

$[\mathrm{dca}]^{-}$<smiles>O=S(=O)(NS(=O)(=O)C(F)(F)F)C(F)(F)F</smiles>

$\left[\mathrm{NTf}_{2}\right]^{-}$

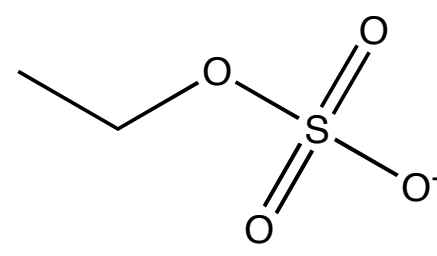

$\left[\mathrm{EtSO}_{4}\right]^{-}$ 


\section{Sensing Platform: lonic liquids}

- An alternative working electrode

- Carbon Cloth- Graphitized Spun Yarn Carbon Fabrics

- Fabric tailor-ability results from controlling the yield on rovings and yarns, and allows for a variety of finished composite thicknesses.

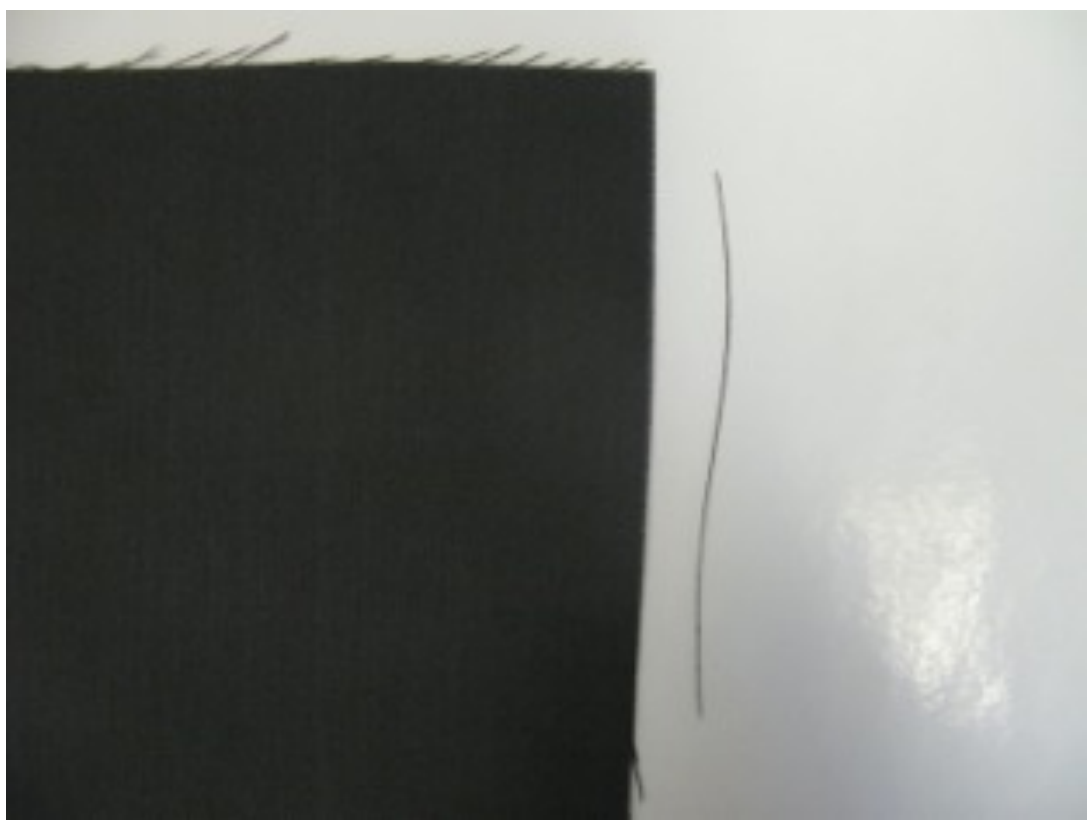




\section{Sensing Platform: lonic liquids}

- An

- Car

- Fab and $y$ thick

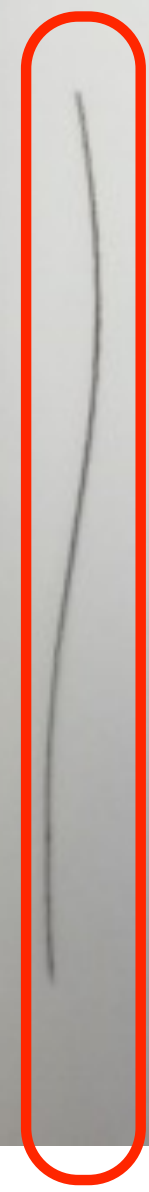

ngs 


\section{Sensing Platform: Ionic liquids}

- Counter \& working electrode consisted of carbon cloth graphitized Spun Yarn Carbon Fabrics

- $500 \mu \mathrm{m}$ threads consisting of a bundle of $10 \mu \mathrm{m}$ fibres. Allows for flexible substrates.

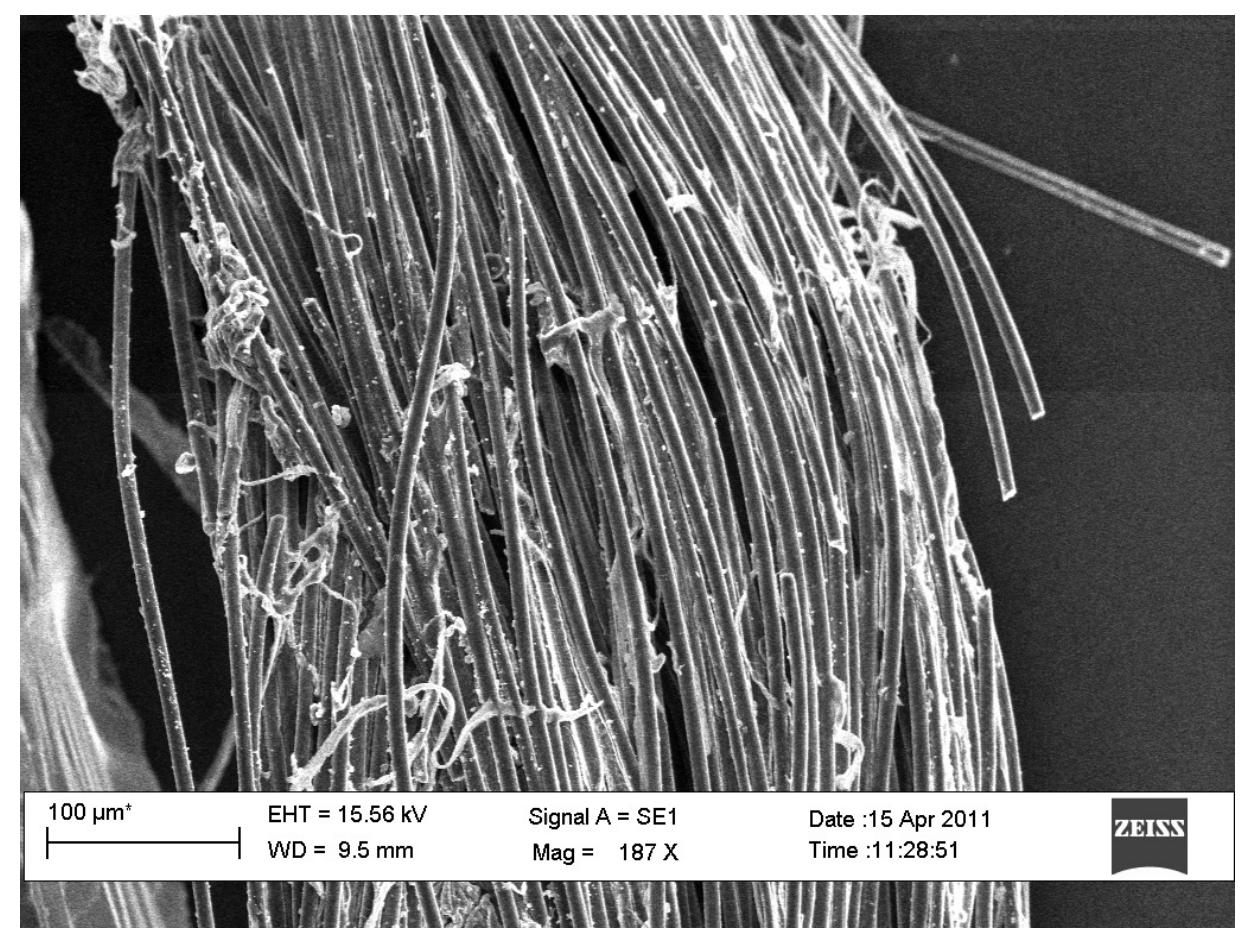

ONCSR 


\section{Sensing Platform: lonic liquids}

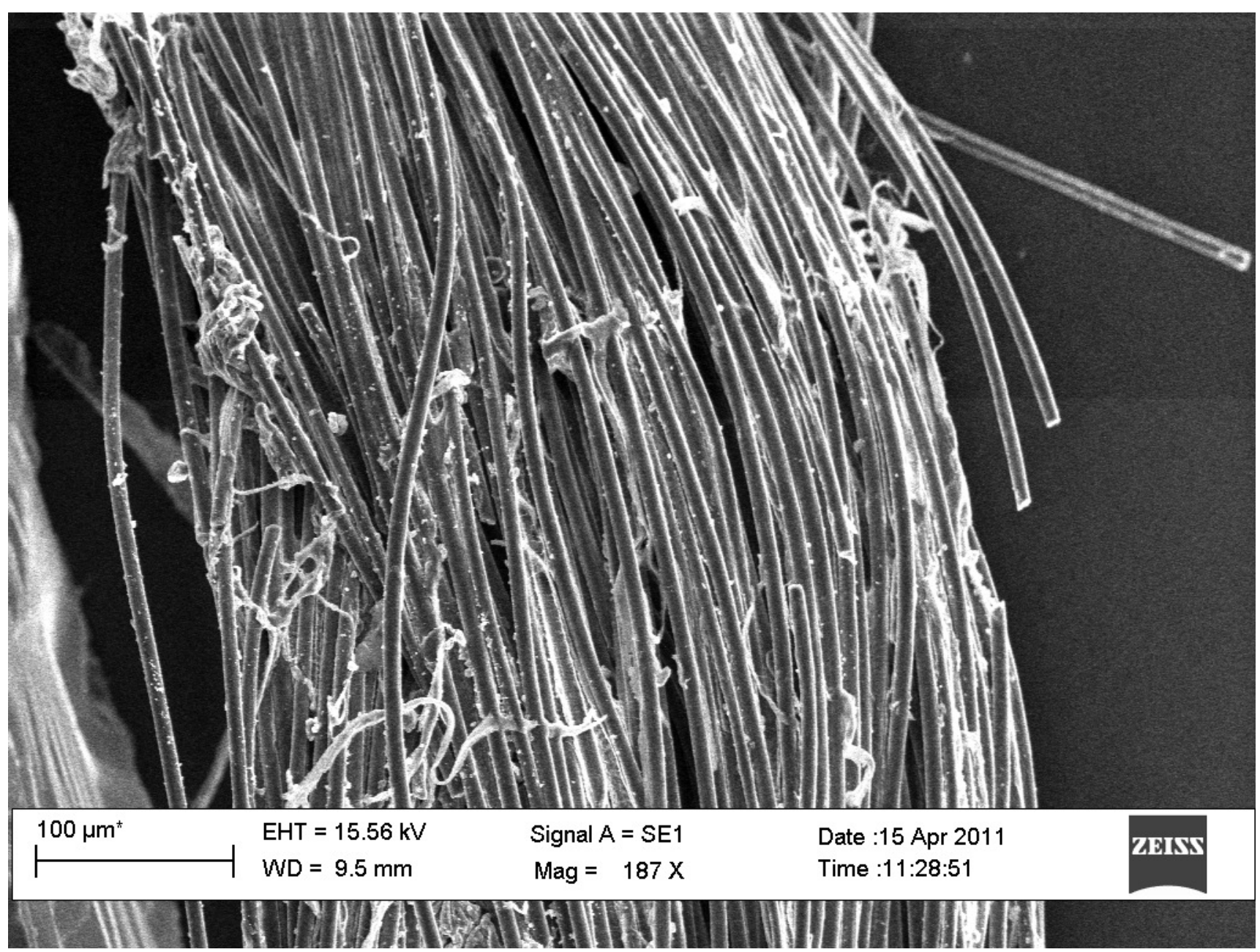

ONCSR 


\section{Sensing Platform: lonic liquids}

- Potentials were against a $\mathrm{Ag} / \mathrm{AgCl}$ reference electrode - $500 \mu \mathrm{m}$ silver wire chloridised in $\mathrm{FeCl}_{3}$.

- Single threads were soaked in a IL / Ferrocene / GOx enzyme solution.

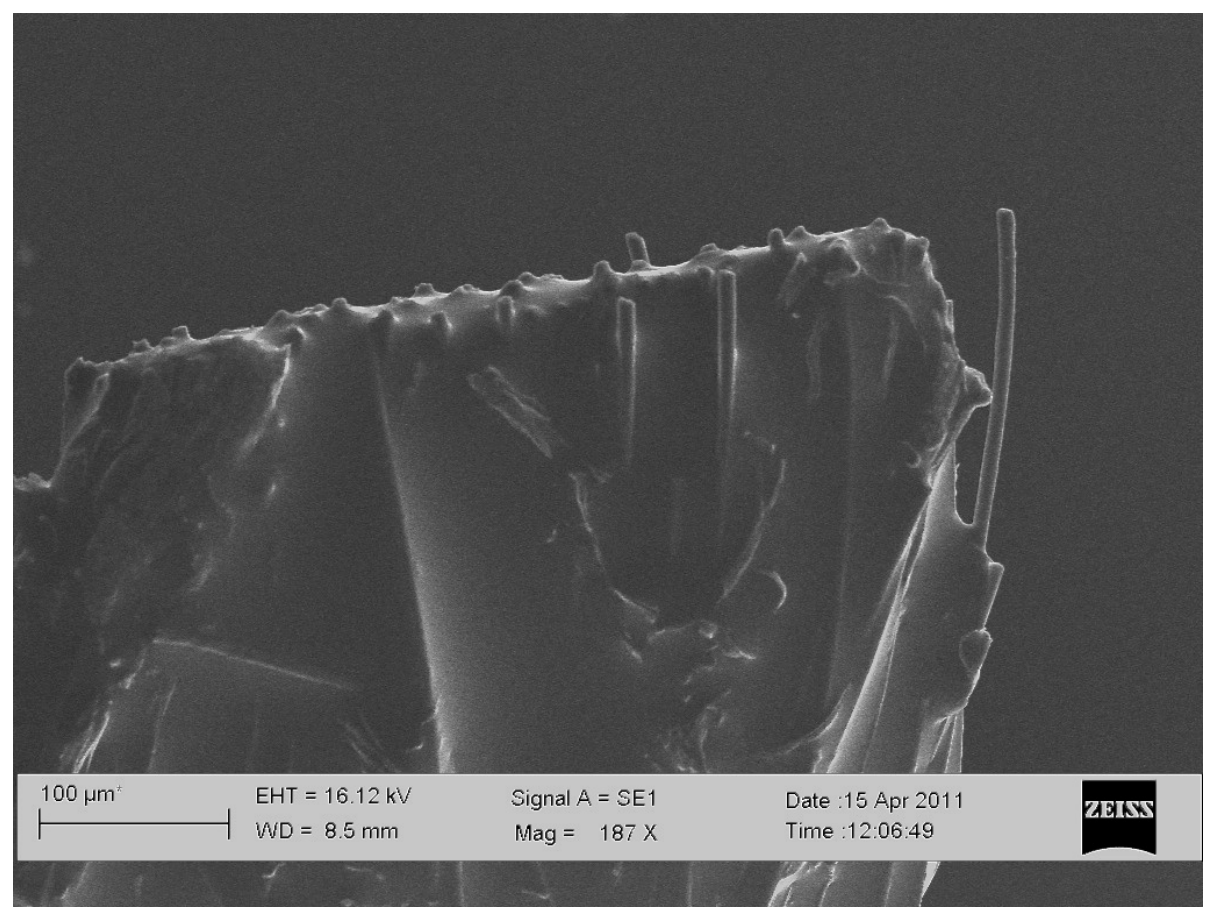




\section{Sensing Platform: Ionic liquids}

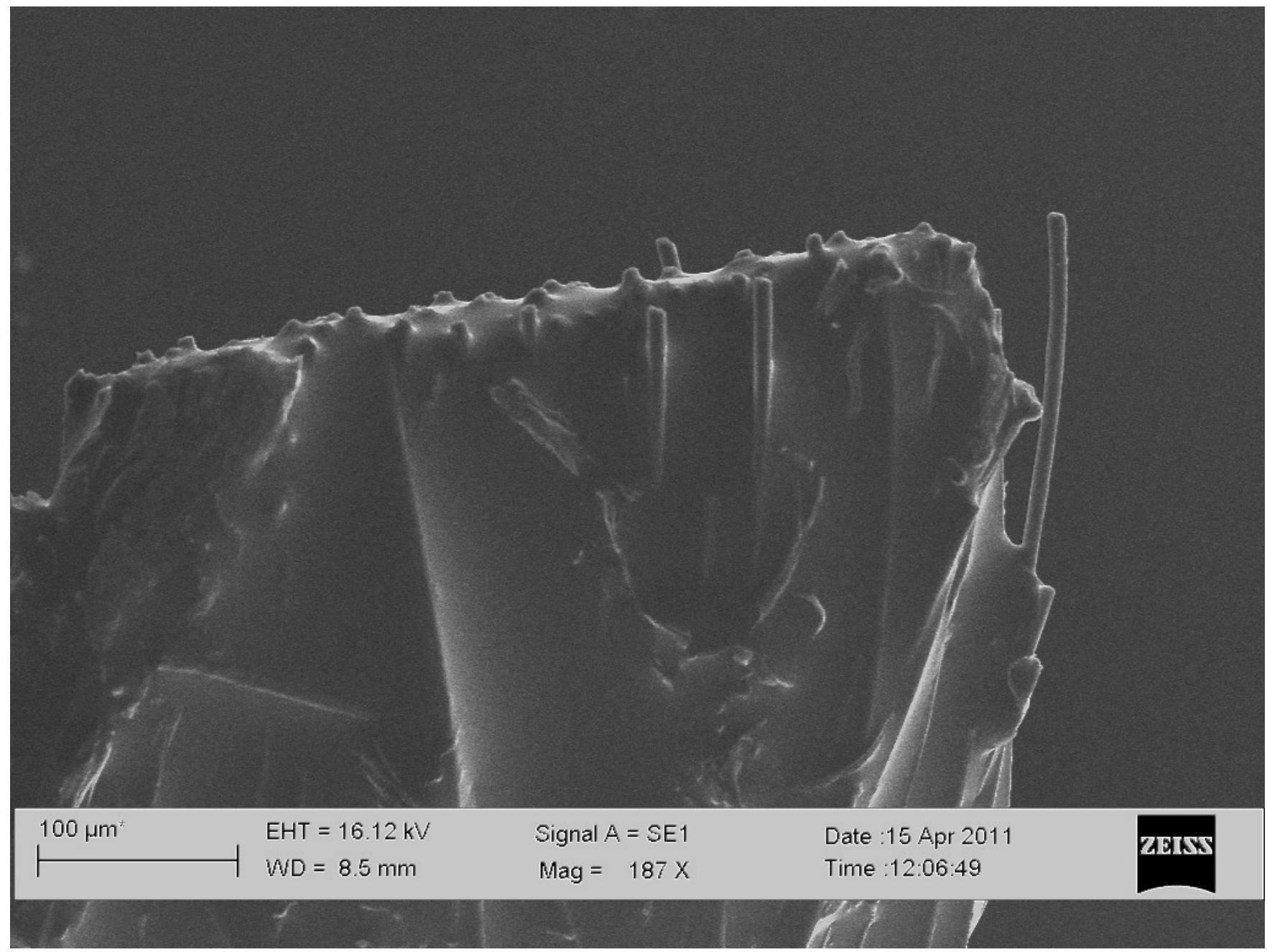

ONCSR 


\section{Sensing Platform: Ionic liquids}

- The electrochemical mechanism for glucose detection in a Ferrocene mediated system ${ }^{[15]}$ :

GOx-FAD + Glucose $\rightarrow$ GOx-FADH $2+$ Gluconolactone $2 \mathrm{Fe}^{+3}+\mathrm{GOx}-\mathrm{FADH}_{2} \rightarrow 2 \mathrm{Fe}^{+2}+\mathrm{GOx}^{+\mathrm{FAD}^{+}}$ $2 \mathrm{Fe}^{+2} \rightarrow 2 \mathrm{Fe}^{+3}+2 \mathrm{e}^{-}$

(a) electrode surface 


\section{Sensing Platform: Ionic liquids}

CLARITY

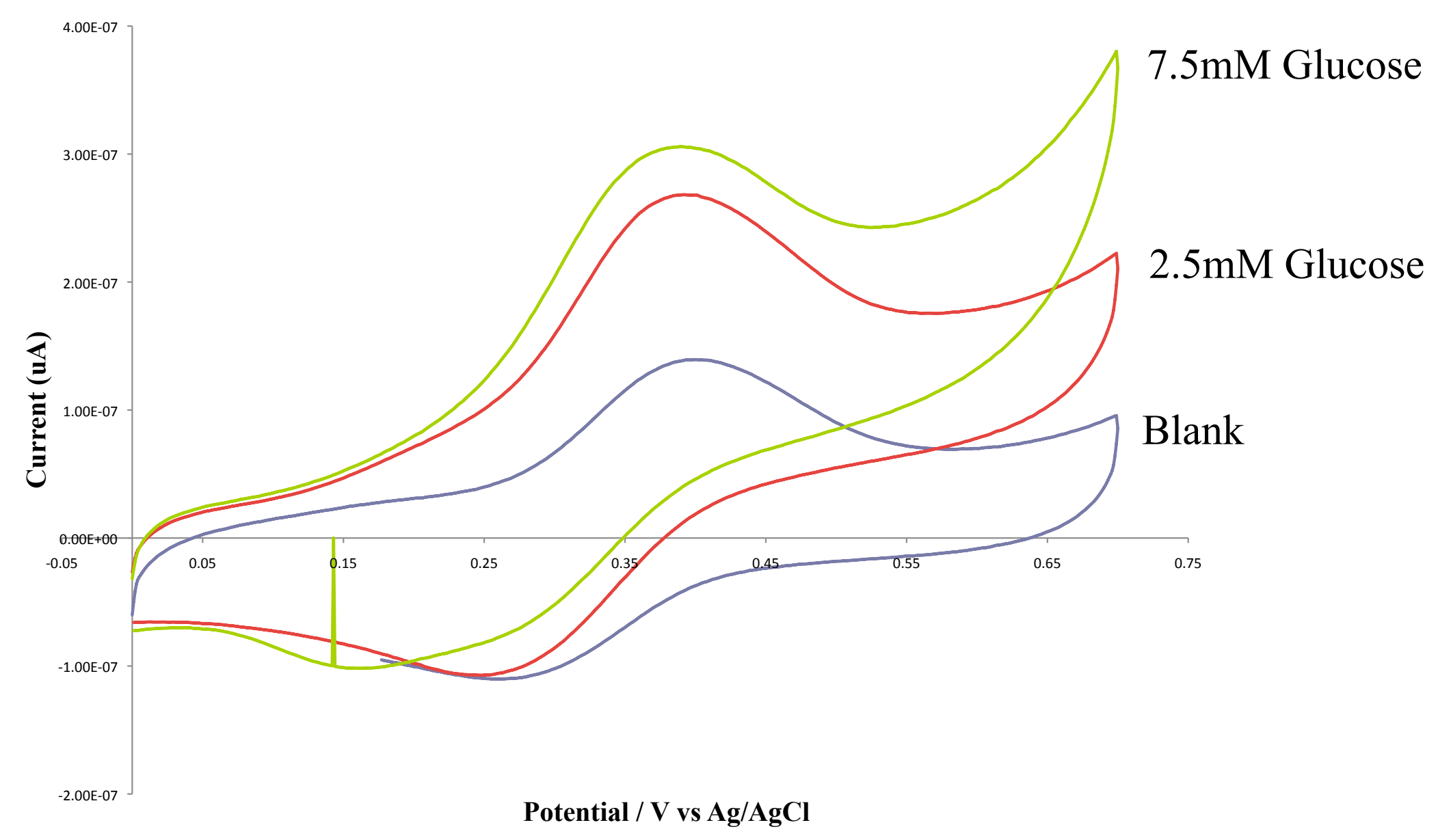

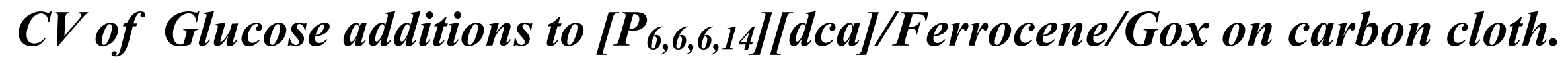
Scan rate $0.01 \mathrm{~V} / \mathrm{S}$ 


\section{Sensing Platform: lonic liquids}

- Using the Anson equation, the calculated working area was approx $0.138 \mathrm{~cm}^{2}$.

$$
Q=\frac{2 n F A C_{o} D_{o}^{1 / 2}}{\pi^{1 / 2}} t^{1 / 2}
$$

- Due to the hydrophobic nature of the cloth, $\left[\mathrm{P}_{6,6,6,14}\right][\mathrm{dca}]$ was chosen as the electrolyte. 


\section{Sensing Platform: lonic liquids}

\section{Quick summary}

- Carbon cloth shows potential as a flexible working electrode.

- Can be woven into sports athletes clothing.

- Durable, flexible sensing platform.

- $\left[\mathrm{P}_{6,6,6,14}\right][\mathrm{dca}]$ as an electrolyte in the glucose system shows favourable limit of detection

- A flexible, wearable one shot sensor maybe produced using IL formulations 


\section{Sensing Platform: lonic liquids}

\section{Organic Electrochemical Transistors (OECTs)}

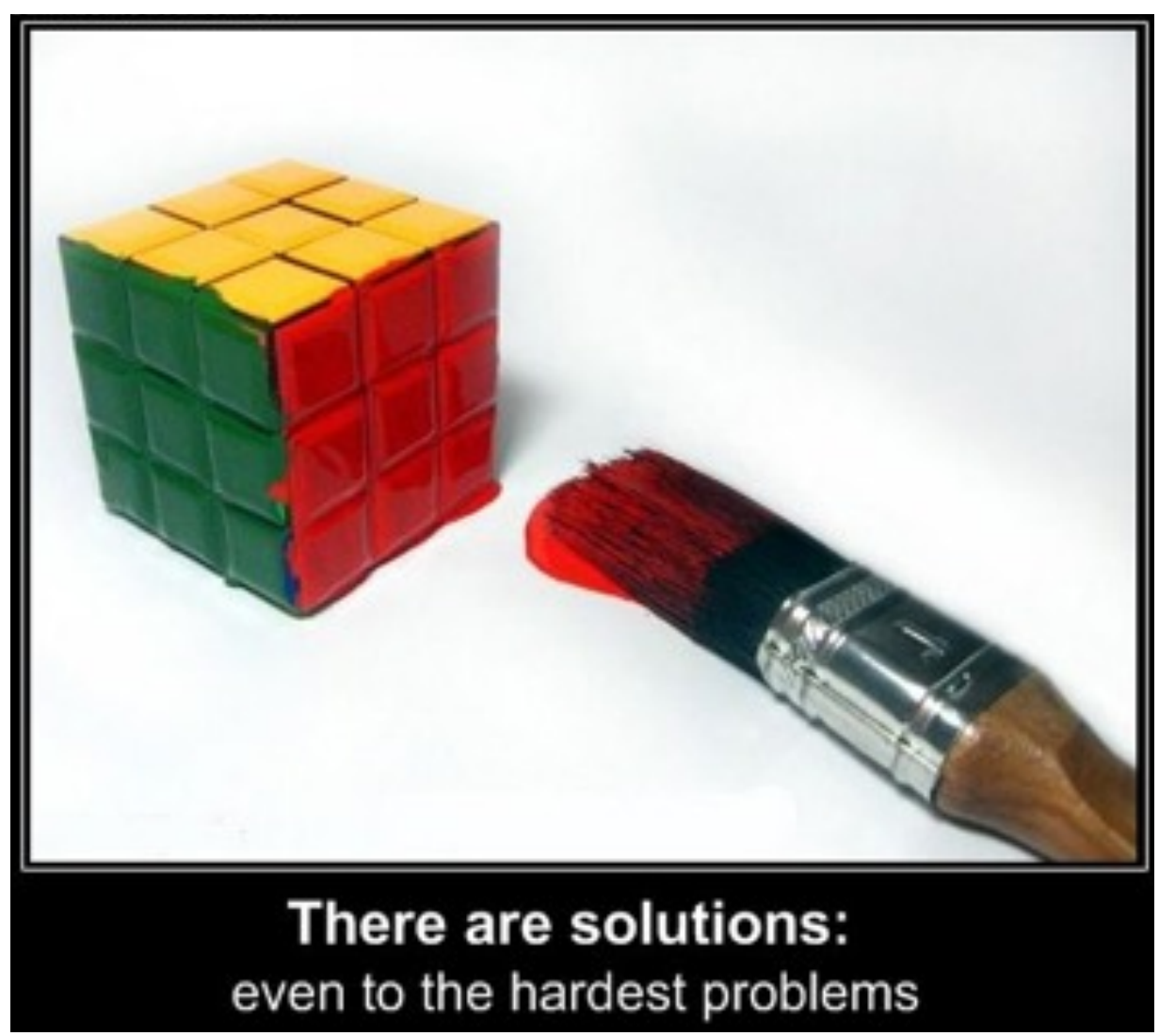

Poster this evening: $8118-29$ 


\section{Sensing Platform: lonic liquids}

The Aim:

- To develop an enzymatic sensor based on an OECT that uses an IL as an integral part of its structure.

- The strategy involves patterning the RTIL over the active area of the OECT, and using it as a reservoir for the enzyme and the mediator.

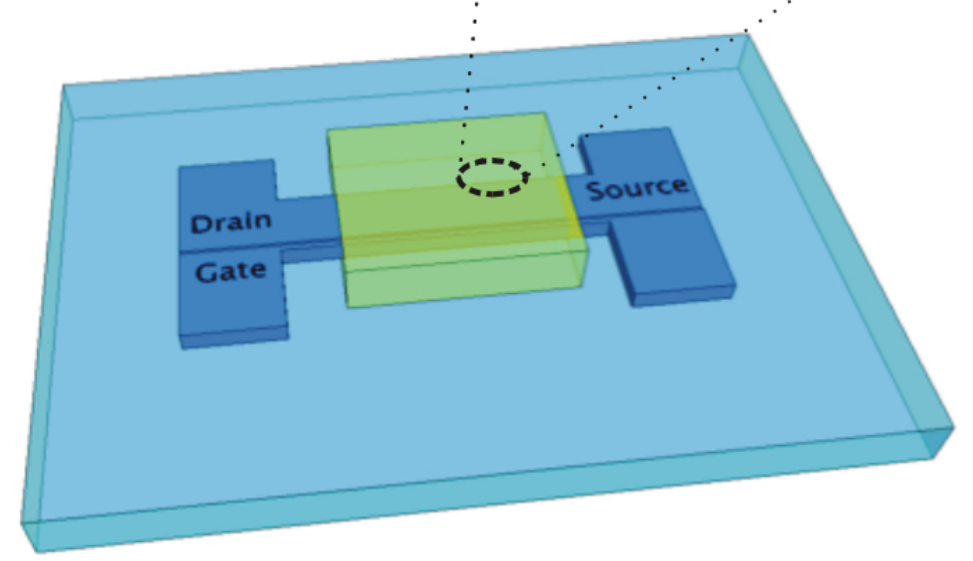




\section{Sensing Platform: lonic liquids}

- Important properties of the electrolyte for this device must include wetting the PEDOT : PSS film. 


\section{Sensing Platform: lonic liquids}

- Important properties of the electrolyte for this device must include wetting the PEDOT : PSS film.

- This allows the enzyme and the mediator to be patterned over the active area of the device.

- The IL should be miscible with the aqueous phase (PBS).

- Triisobutyl(methyl)phosphonium Tosylate $\left(\left[\mathrm{P}_{1,4,4,4}\right][\mathrm{Tos}]\right)$ due to the hydrophilic nature of the cation / anion.
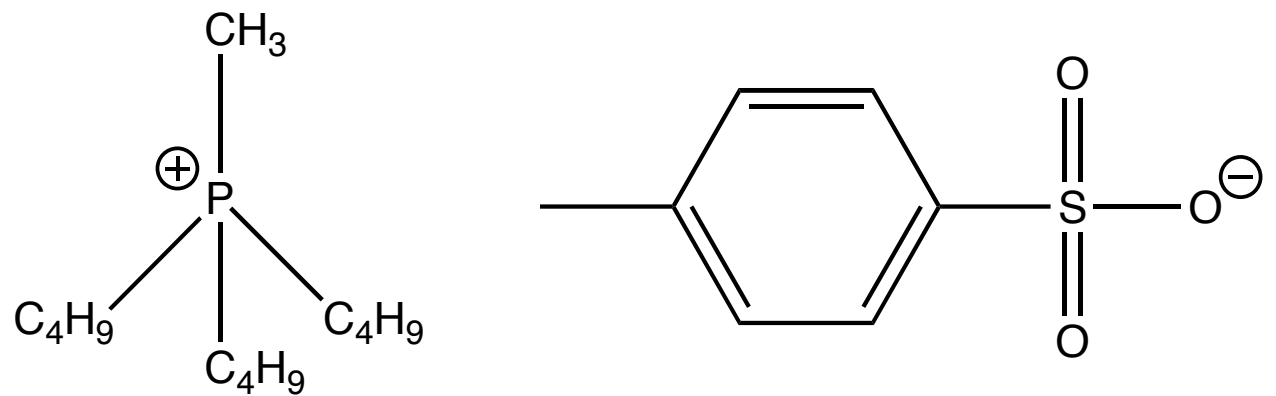


\section{Sensing Platform: lonic liquids}

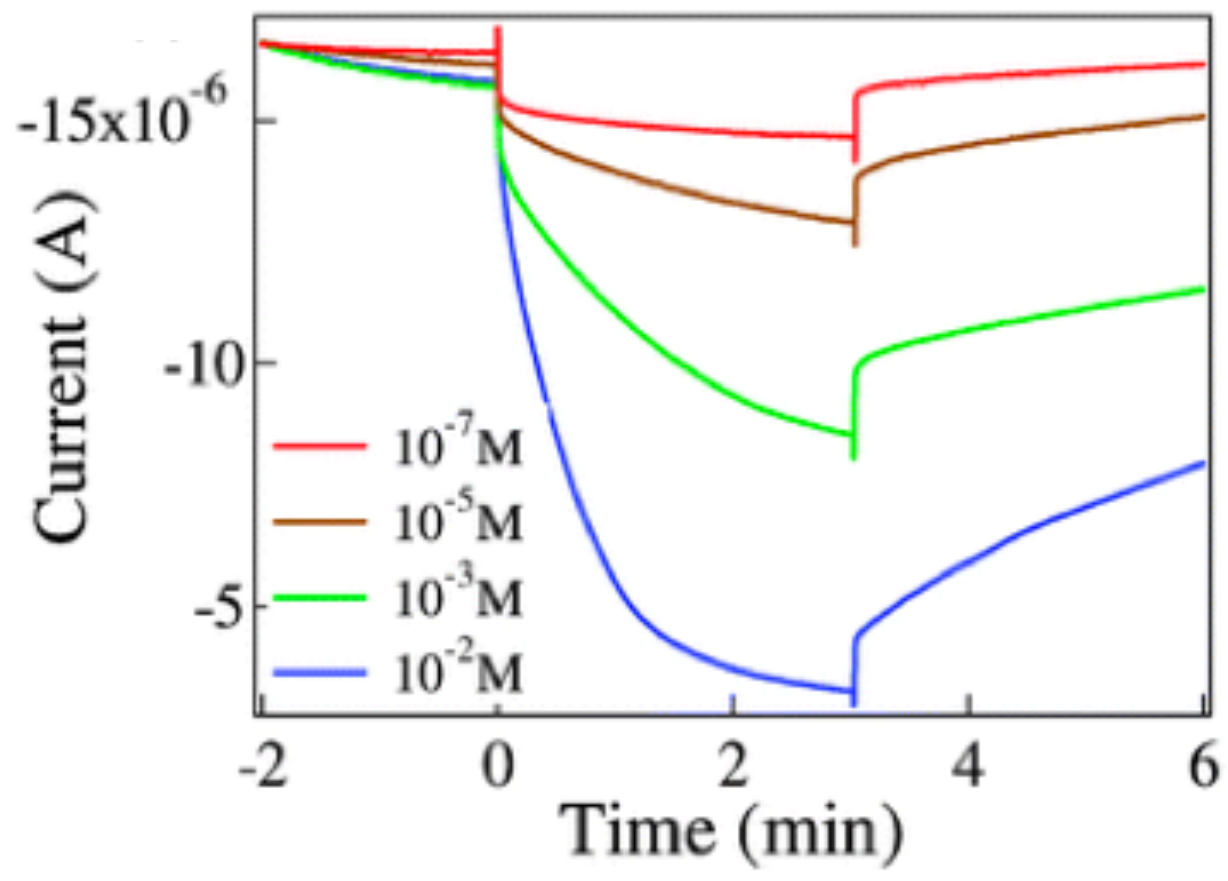

- The transient response of the drain current of an OECT upon application of a gate voltage of $0.4 \mathrm{~V}$ and duration of $3 \mathrm{~min}$. The drain voltage was $-0.2 \mathrm{~V}$. 


\section{Sensing Platform: lonic liquids}

- Current modulation of the OECT as a function of glucose concentration.

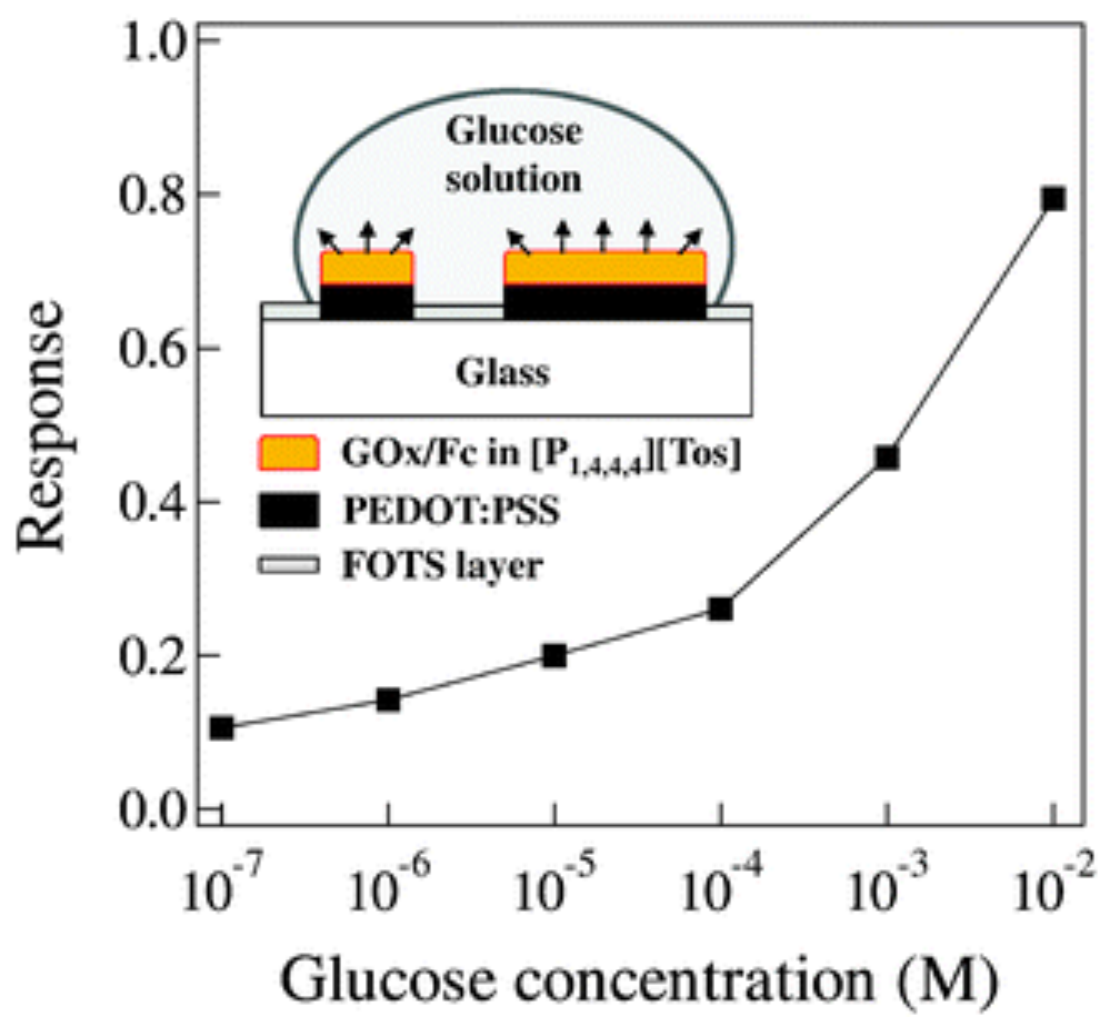

- Inset shows the concept of device operation, and the arrows indicate the dissolution of the RTIL carrying the enzyme and the mediator into the analyte solution. 


\section{Sensing Platform: lonic liquids}

- The data show the characteristic decrease of drain current upon gating which has been understood on the basis of the reactions shown below

(A)

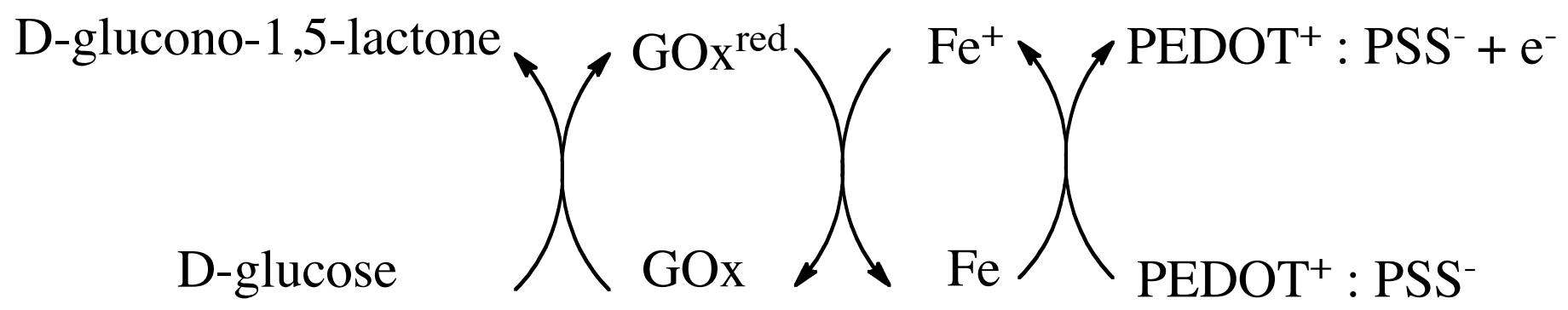

(B) $\quad$ PEDOT $^{+}: \mathrm{PSS}^{-}+\mathrm{M}^{+}+\mathrm{e}^{-}$

$\longrightarrow$ PEDOT $+\mathrm{M}^{+}: \mathrm{PSS}^{-}$

Reactions at the gate electrode (a) and at the channel (b) of the OECT. 


\section{Sensing Platform: lonic liquids}

(A)

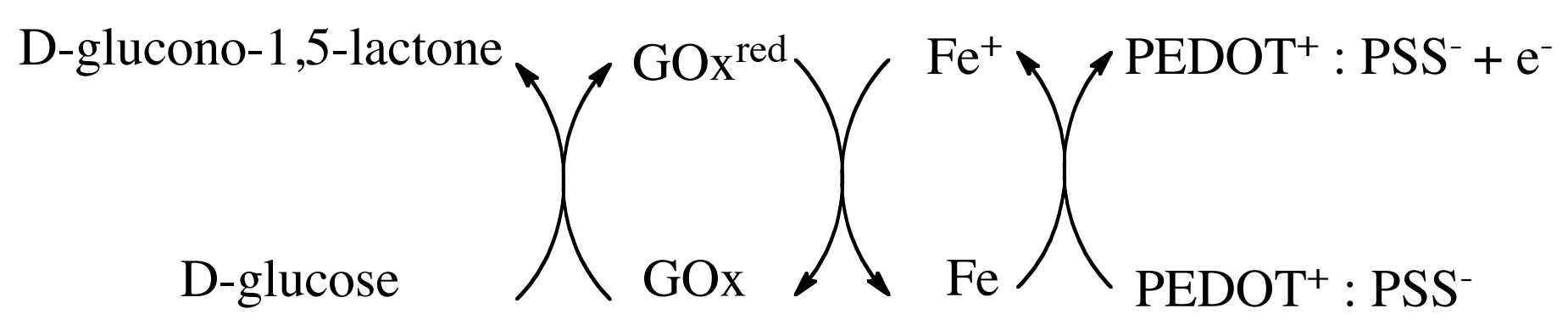

(B) $\quad$ PEDOT $^{+}: \mathrm{PSS}^{-}+\mathrm{M}^{+}+\mathrm{e}^{-}$

$\longrightarrow$ PEDOT $+\mathrm{M}^{+}:$PSS $^{-}$

- As glucose in the solution is oxidised, the enzyme (GOx) itself is reduced, and cycles back with the help of the $\mathrm{Fc} /$ ferricenium ion $(\mathrm{Fc}+)$ couple, which shuttles electrons to the gate electrode (A).

- For example, for $10^{-2} \mathrm{M}$ of glucose, this cascade of reactions causes a current of $8 \times 10^{-8} \mathrm{~A}$ to flow to the gate electrode.

-At the same time, cations from the solution $(\mathrm{M}+)$ enter the PEDOT : PSS channel and dedope it. (B) 


\section{Sensing Platform: lonic liquids}

\section{Conclusions:}

- Successful integration of an OECT with an IL as electrolyte. 


\section{Sensing Platform: lonic liquids}

\section{Conclusions:}

- Successful integration of an OECT with an IL as electrolyte.

- The ionic liquid was confined on the surface of the transistor using a photolithographically patterned hydrophobic monolayer.

-The enzyme was in a dispersed state in the ionic liquid, which may prove to be a good strategy for improving long-term storage.

- Using the glucose/glucose oxidase pair as a model, it was demonstrated the analyte detection in the $10^{-7}$ to $10^{-2} \mathrm{M}$ concentration range. 


\section{Electrochemical biosensing: The road ahead}

- Currently for applications in materials science, there is a growing interest in 'ionogels'.

- Polymers with ionic liquids integrated such that they retain their specific properties within the polymer/gel environment. 


\section{Electrochemical biosensing: The road ahead}

\section{Ionogel synthesis:}

Inorganic route: Oxides, Sol-Gel. ${ }^{[17]}$

- Applications in catalysis \& photonics. 


\section{Electrochemical biosensing: The road ahead}

\section{Ionogel synthesis:}

Inorganic route: Oxides, Sol-Gel. ${ }^{[17]}$

- Applications in catalysis \& photonics.

Organic route: Polymers, Acrylamide gels [18]

- Applications in solid state electrolytes and separations 


\section{Electrochemical biosensing: The road ahead}

\section{Ionogel synthesis:}

Inorganic route: Oxides, Sol-Gel.

- Applications in catalysis \& photonics.

Organic route: Polymers, Acrylamide gels ${ }^{[18]}$

- Applications in solid state electrolytes and separations 


\section{Electrochemical biosensing: The road ahead}

\section{Ionogel synthesis:}

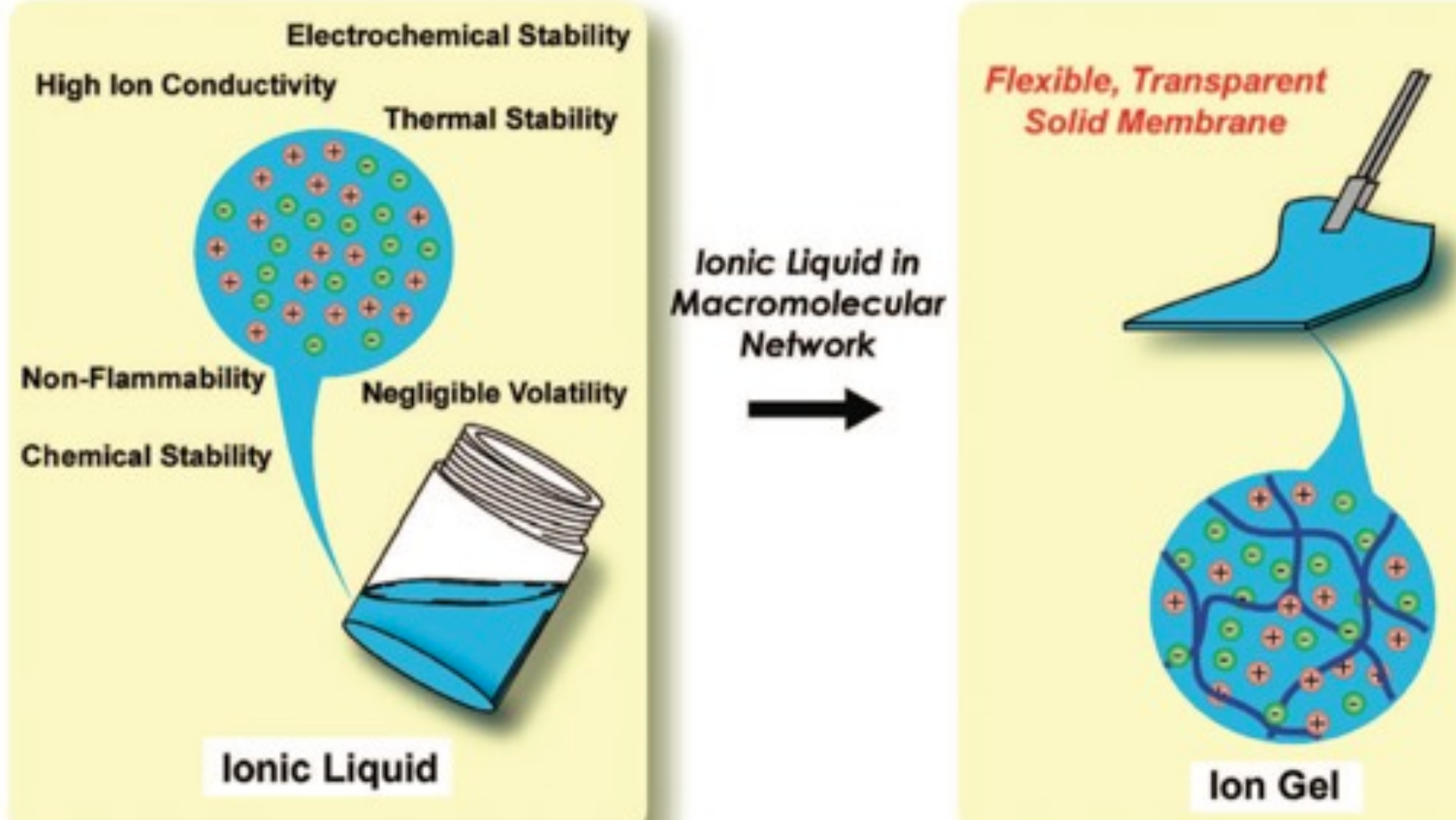

[17] M.-A. Nouze, J. L. Bideau, P. Gaveau, S. Bellayer and A. Vioux, Chem. Mater, 2006, 18, 3931-3936. [18] T. Ueki and M. Watanabe, Macromolecules, 2008, 41, 3739-3749. 


\section{Electrochemical biosensing: The road ahead}

Ionogel synthesis: Organic route

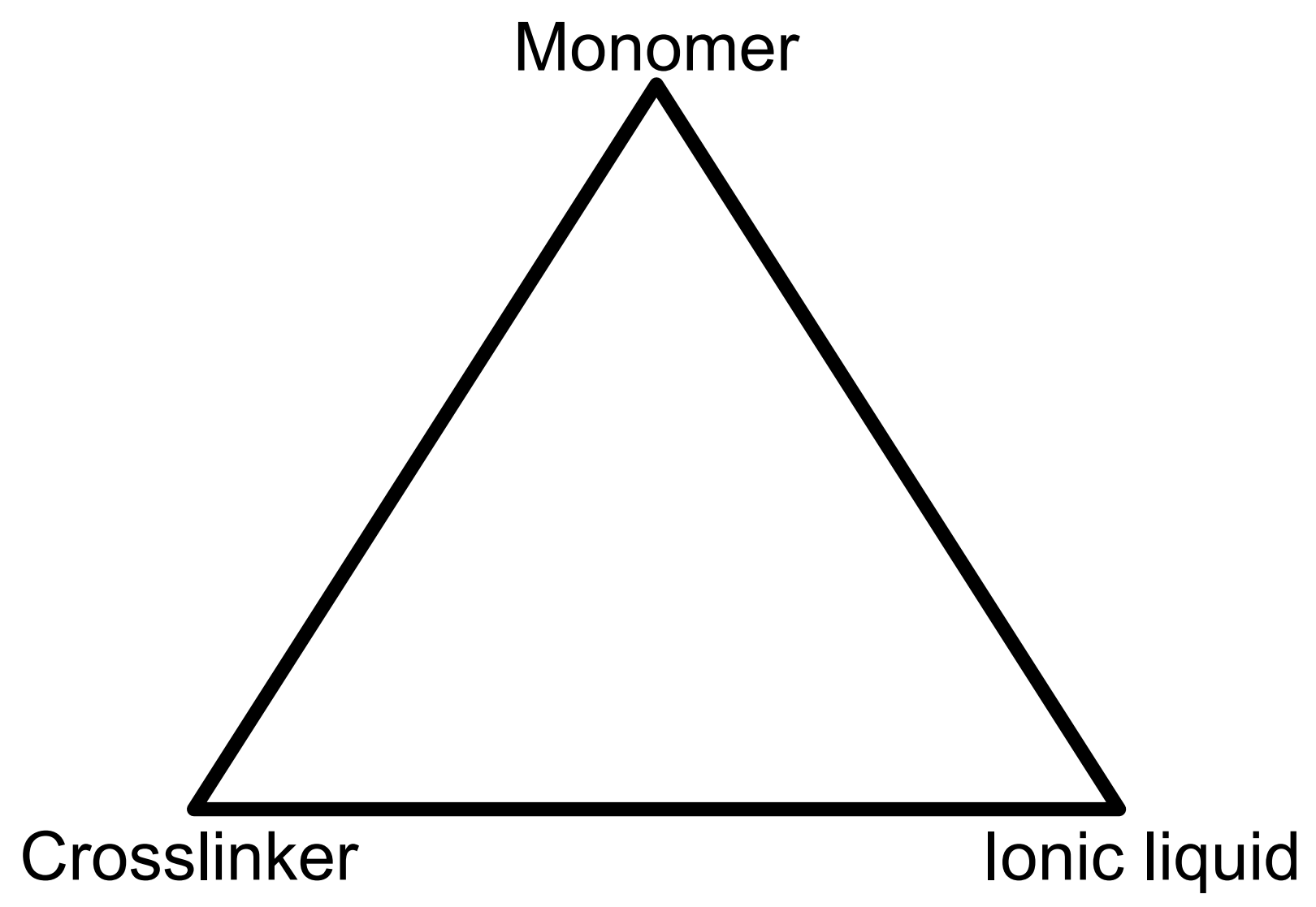




\section{Electrochemical biosensing: The road ahead}

Ionogel synthesis: Organic route

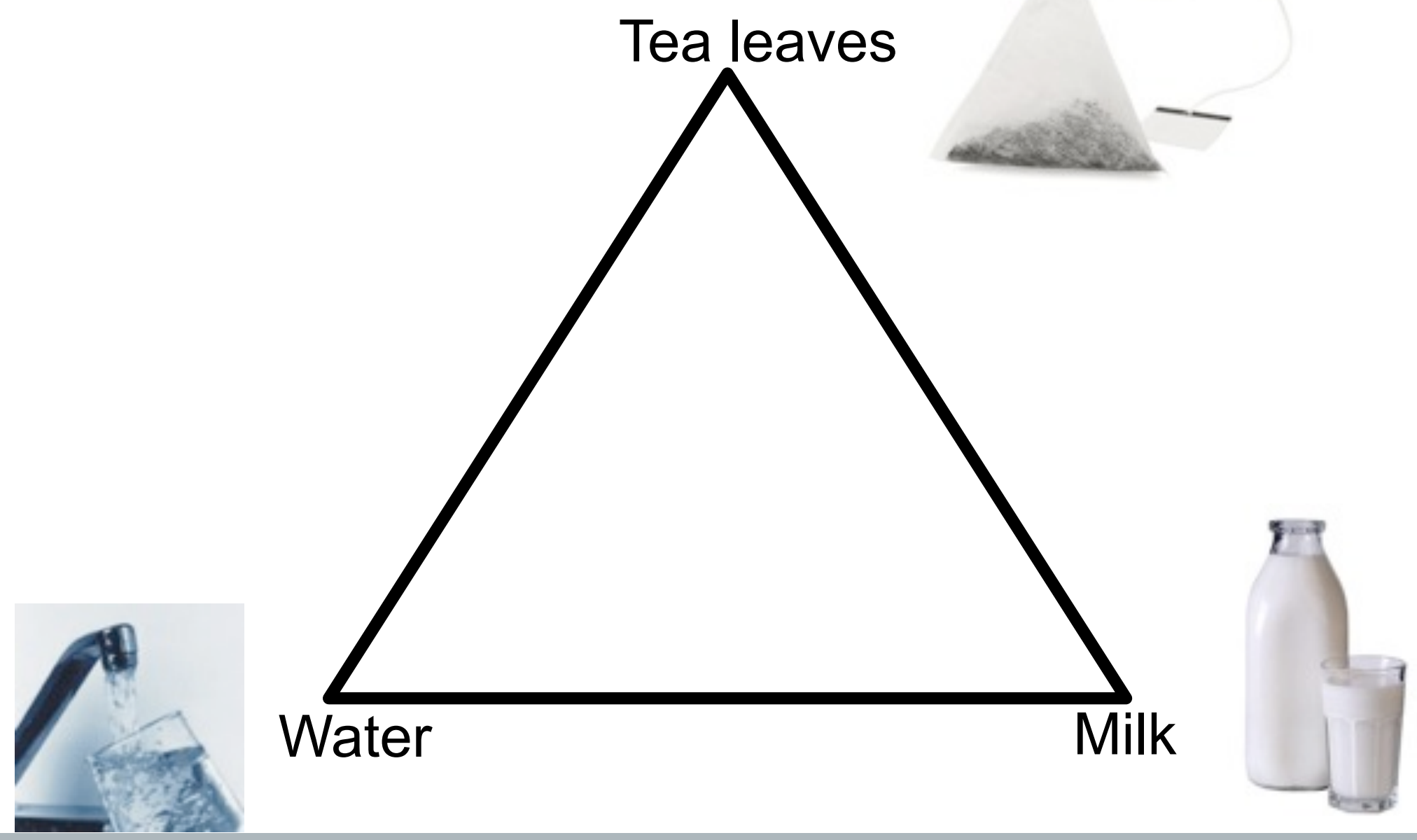




\section{Electrochemical biosensing: The road ahead}

Chem Soc Rev

Cite this: DOI: $10.1039 / \mathrm{cocs} 00059 \mathrm{k}$

www.rsc.org/csr

CRITICAL REVIEW

Ionogels, ionic liquid based hybrid materials $\dagger$

Jean Le Bideau, ${ }^{a}$ Lydie Viau ${ }^{b}$ and André Vioux ${ }^{{ }^{b}}$

Received 30th July 2010

DOI: $10.1039 / \mathrm{cos} 00059 \mathrm{k}$

An excellent review by Le Bideau et. al.[19]

Dynamic Article Links

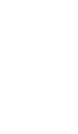




\section{Electrochemical biosensing: The road ahead}

- Incorporate printable formulations onto OECTs for biosensing
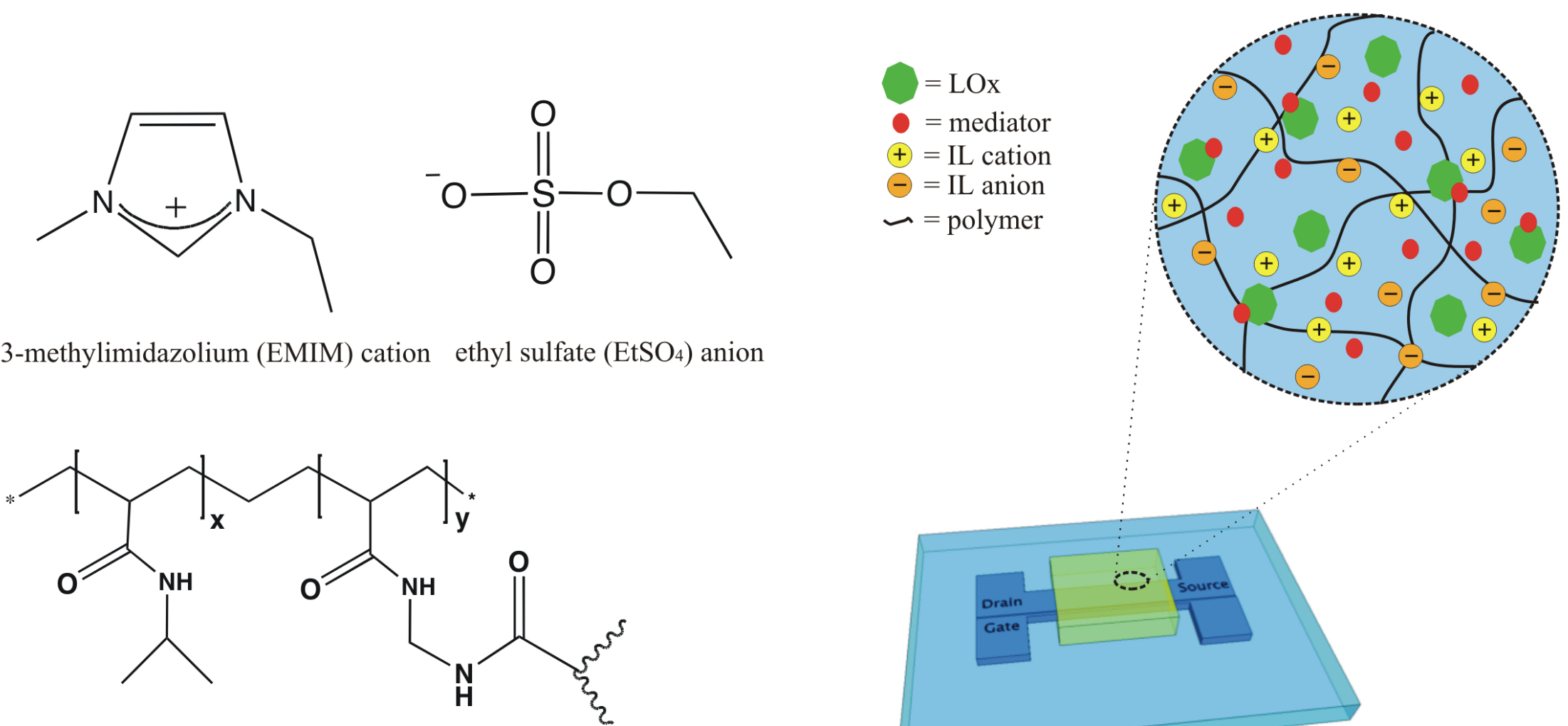

poly ( $N$-isopropylacrylamide-co- $N, N$ '-methylenebisacrylamide)

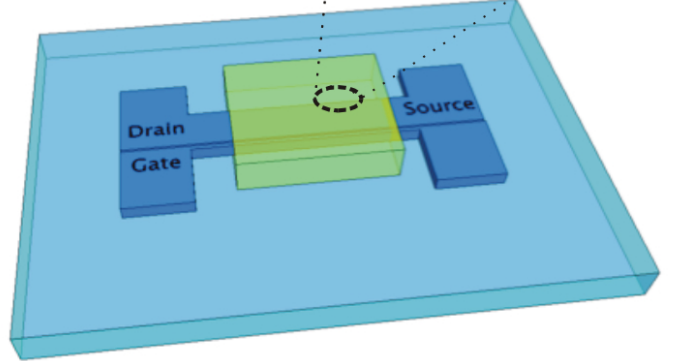

ONCSR 


\section{Electrochemical biosensing: The road ahead}

\section{Flexible Wearable Transistor}

\section{Printing lonogel}

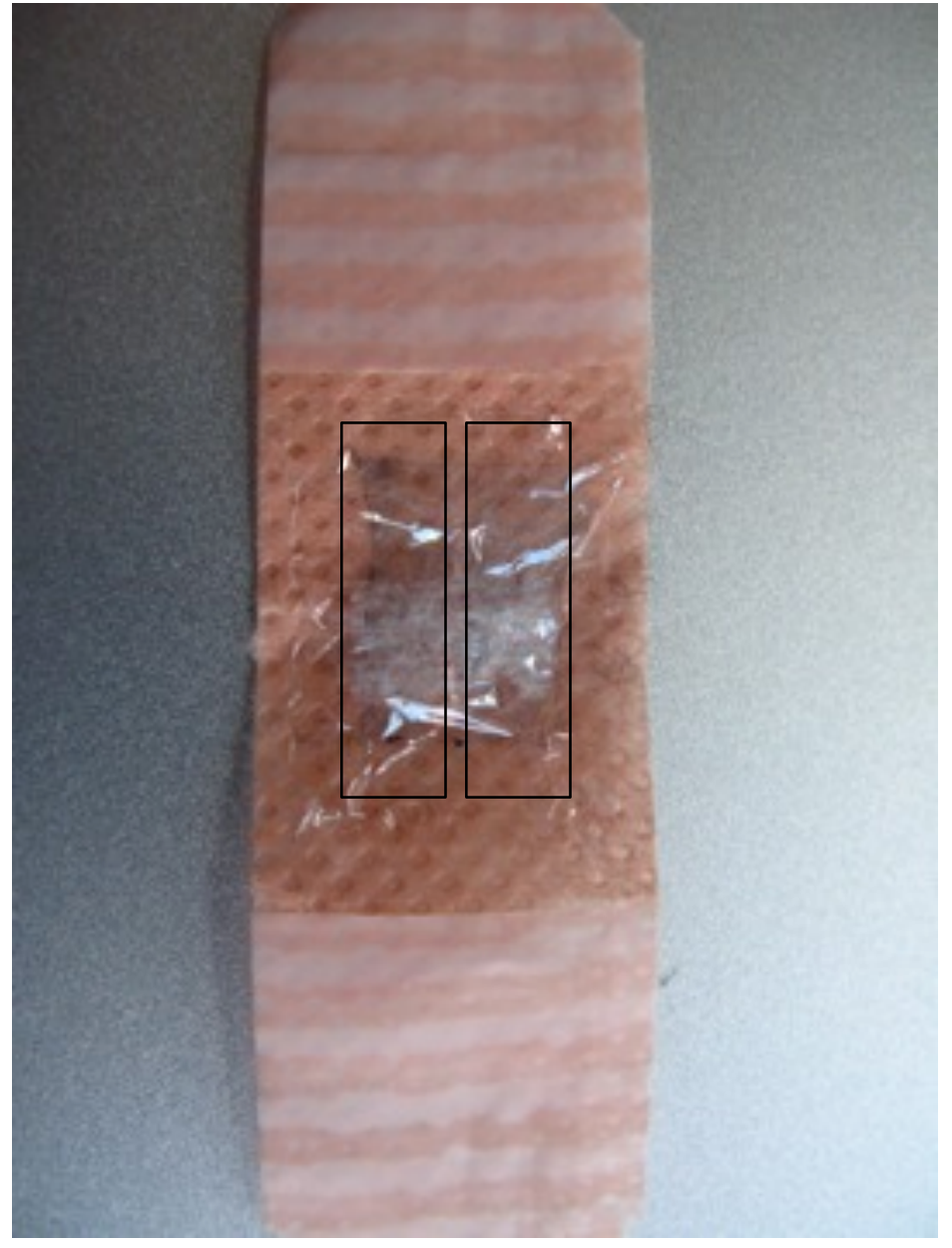

$\sim 625 \mathrm{nl}$

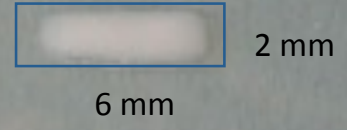

150 um thickness 


\section{Electrochemical biosensing: The road ahead}

\section{Advantages of lonogels}

- Control the Ratio of cross linker to IL. 


\section{Electrochemical biosensing: The road ahead}

\section{Advantages of lonogels}

- Control the Ratio of cross linker to IL.

- Less crosslinker, less dense polymer. Diffusion is improved

- Catalytically active proteins and enzymes may also be confined.

- It is therefore proposed that having "Ionogels" is a particularly attractive strategy in the field of biosensing.

- These materials, in theory, will inherit all of the favourable IL properties whilst being in a solid, semi-solid gel like structure. 


\section{Acknowledgments}

Wearable Sensors

Dr Shirley Coyle

Dr Ben Schazmann

Vincenzo F. Curto

Caroline Barry

Dr Susan Warren

Dr Eithne Dempsey

Prof Douglas MacFarlane

Prof Dermot Diamond
IL / Transistor work

Dion Khodagholy

Prof George Malliaras

Prof Róisín Owens

Dr Fabio Cicoira

Dr Sang Yoon Yang

Prof Dermot Diamond

Dr Fernando Benito-Lopez

Dr Robert Byrne 


\section{Acknowledgments}

\section{Funding Agencies}

\section{QYTEC}

DCU
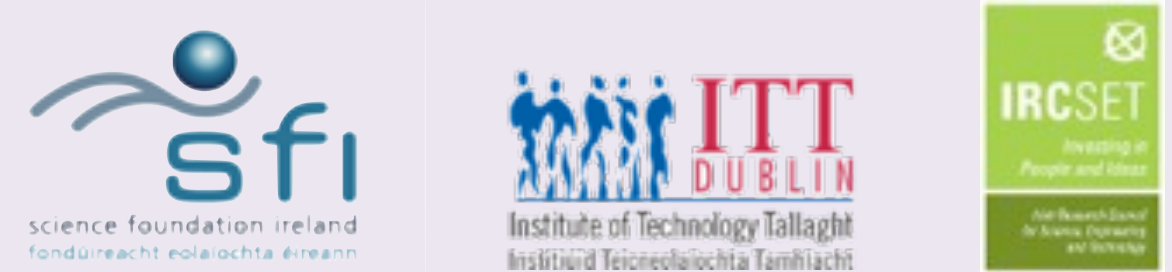

science foundation ireland

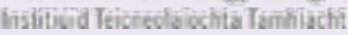

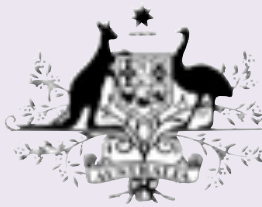

Australian Government

Australian Research Council

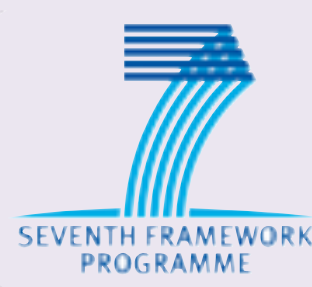




\section{Thanks for your attention}
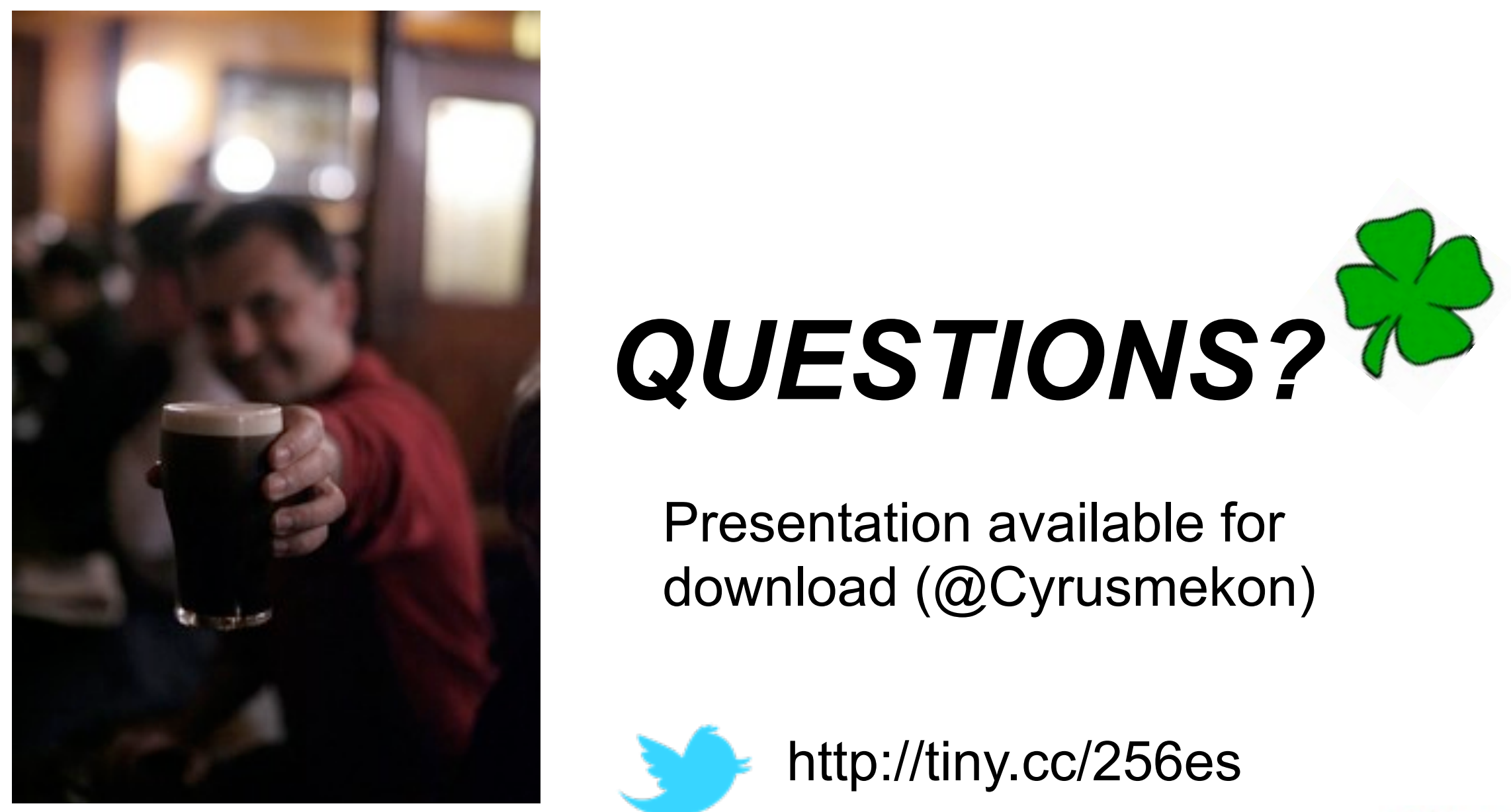

Presentation available for download (@Cyrusmekon)

http://tiny.cc/256es 